\section{Variation for Heat Tolerance During Seed Germination in Diverse Carrot [Daucus carota (L.)] Germplasm}

\author{
Adam Bolton ${ }^{1}$ \\ Department of Horticulture, University of Wisconsin-Madison, 1575 Linden \\ Drive, Madison, WI 53706
}

Aneela Nijabat ${ }^{1}$
Department of Botany, University of Sargodha, Sargodha-40100, Pakistan

Muhammad Mahmood-ur-Rehman

Institute of Horticultural Sciences, University of Agriculture Faisalabad 38000, Pakistan

\author{
Naima Huma Naveed \\ Department of Botany, University of Sargodha, Sargodha-40100, Pakistan
}

A.T.M. Majharul Mannan

Department of Horticulture, Bangladesh Agricultural University, Mymensingh2202, Bangladesh

\section{Aamir Ali \\ Department of Botany, University of Sargodha, Sargodha-40100, Pakistan}

Mohamed A. Rahim

Department of Horticulture, Bangladesh Agricultural University, Mymensingh2202, Bangladesh

\section{Philipp Simon ${ }^{2}$}

Department of Horticulture, University of Wisconsin-Madison, 1575 Linden Drive, Madison, WI 53706; and U.S. Department of Agriculture-ARS, Vegetable Crop Unit, Department of Horticulture, University of Wisconsin-Madison, 1575 Linden Drive, Madison, WI 53706

Additional index words. breeding, diversity, Daucus carota, germplasm, heat, salinity

\begin{abstract}
Carrot production is constrained by high levels of heat stress during the germination stage in many global regions. Few studies have been published evaluating the effect of heat stress on carrot seed germination or screening for genetic heat stress tolerance. The objectives of this study were to evaluate the response of diverse carrot germplasm to heat stress, identify heat-tolerant germplasm that may be used by plant breeders, and define the appropriate temperature for assessing heat tolerance in germinating carrot seed. To identify an appropriate screening temperature, three commercial hybrids and an open pollinated variety were evaluated at five temperatures $\left(24,32.5,35,37.5\right.$, and $\left.40{ }^{\circ} \mathrm{C}\right)$. In preliminary studies, $35^{\circ} \mathrm{C}$ was identified as the optimal temperature for screening heat tolerance of carrot seed. Cultivated and wild carrot plant introductions $(P I s)(n=270)$ from the U.S. Department of Agriculture (USDA) National Plant Germplasm System (NPGS) representing 41 countries, inbred lines from the USDA Agricultural Research Service $(n=15)$, and widely grown commercial hybrids $(n=8)$ were evaluated for heat tolerance under heat stress and nonstress conditions $\left(35^{\circ} \mathrm{C}\right.$ and $24^{\circ} \mathrm{C}$, respectively) by calculating absolute decrease in percent germination (AD), inhibition index (II), relative heat tolerance (RHT), and heat tolerance index (HTI). All measurements of heat tolerance identified significant differences among accessions; AD ranged from $-13.0 \%$ to $86.7 \%$, II ranged from $35.7 \%$ to $100.0 \%$, RHT ranged from 0 to 1.36 , and HTI ranged from 0.0 to 1.45 . The broad-sense heritability $\left(\mathbf{H}^{2}\right)$ calculations ranged from $\mathbf{0 . 6 4}$ to 0.86 for different traits, indicating a moderately strong genetic contribution to the phenotypic variation. Several wild carrot accessions and inbred lines displayed low levels of heat tolerance, whereas cultivated accessions PI 643114 (United States), PI 652400 and PI 652403 (Turkey), PI 652208 (China), and PI 652403 (Russia) were most heat tolerant. This is the first evaluation of heritability for heat stress tolerance during carrot seed germination, the first measure of HTI, and the first correlation calculation between heat and salt tolerance during germination in carrot.
\end{abstract}

The ambient temperature of our planet has significantly increased over the past century $\left(0.13^{\circ} \mathrm{C}\right.$ per decade in last 50 years $)$ as part of current global climate change attributed to anthropogenic activities and natural factors (Rohde et al., 2013). Modern climate models have predicted that mean global temperature will rise by $1.1{ }^{\circ} \mathrm{C}$ by the end of this century and intense heat waves will also occur more frequently (IPCC, 2013). Heat stress, caused by elevated temperature, is a major threat for cereals, fruits, and vegetable production, especially in warm regions of the world (Farooq et al., 2011; Hasanuzzaman et al., 2013). Vegetables are a rich source of essential dietary micronutrients (Graham et al., 1999) but the effects of heat stress on the productivity of most vegetables have yet not been well-characterized (Fahad et al., 2017; Mahmood et al., 2017). It may be anticipated that cool-season vegetables, like carrot, are especially sensitive to heat stress.

Carrot (Daucus carota L., $2 n=2 x=18$ ) is a biennial, cool-season, Apiaceous root vegetable that is a rich dietary source of provitamin A carotenoids ( $\alpha$ - and $\beta$-carotene), which is vital for human development and health (Tanumihardjo, 2012). The optimal germination temperature of carrot is 20 to $30{ }^{\circ} \mathrm{C}$ (Corbineau et al., 1994) and, like most crops, abiotic stress reduces carrot yield (Bano et al., 2014, Kahouli et al., 2014). Heat, drought, and/or salinity-induced stress contributes to the much lower carrot yields in countries like Pakistan and most of South Asia relative to North America or Europe (FAO, 2017).

Previous studies have reported that temperatures higher than $27{ }^{\circ} \mathrm{C}$ can cause significant reduction in root mass, which accounts for the yield of a carrot (Rosenfeld, 2004). High temperature causes heat stress and is considered to be one of the major abiotic factors that limits carrot production because of its adverse effects on seed germination, seedling emergence, and plant growth (Landjeva et al., 2008). Heat tolerance is a complex trait that varies with the severity of stress and plant growth stage. Therefore, there is a need to identify heattolerant carrot germplasm with stable growth and yield under high temperature at various stages of growth. Seedling establishment, vegetative growth, and the reproductive phase of the life cycle in carrot are all critical developmental stages, but without the ability to germinate under heat stress, tolerance at later stages of growth is irrelevant. Heat stress tolerance in seeds is typically a multicomplex and polygenic trait (Senthil-Kumar et al., 2007) that varies from species to species and environmental conditions (intensity and exposure period of stress). It has been demonstrated in previous studies that the seed germination of various crops, including wheat (Balla et al., 2012), maize (Iloh et al., 2014; Riley, 1981), rice (Shah et al., 2011), chick pea (Sleimi et al., 2013), and spinach (Hum-Musser et al., 1999), is adversely affected as temperature increases. 
Several previous studies demonstrated the negative effects of low temperature on carrot seed germination and stand establishment (Nascimento and Pereira, 2007; Pereira et al., 2007; Vieira et al., 2005), but relatively little has been reported about the effects of high temperatures. Vieira et al. (2005) demonstrated that high temperature inhibits carrot seed germination. High temperature affects some physiological and biochemical processes like oxygen requirement during seed imbibitions (Nascimento et al., 2008). There is no known mechanism for thermotolerance in carrot and insufficient information is available to characterize the influence of high temperature on carrot seed germination and biomass production. The most expansive carrot germplasm evaluation, to date, for heat tolerance at the germination stage, was done by Nascimento et al. (2008), who evaluated 34 commercial cultivars and 63 diverse germplasm accessions. They evaluated heat stress traits including ethylene production, time to first germination, and RHT under $35^{\circ} \mathrm{C}$. The current lack of information limits our understanding of heat tolerance mechanisms in carrot. To expand the information needed to better understand those mechanisms, the objectives of this study were to identify the optimal temperature conditions for evaluating heat tolerance in carrot; to evaluate a large carrot germplasm collection for heat tolerance traits, including HTI, II, and $\mathrm{AD}$ at the germination stage; to evaluate the relationship between domestication status and root color on heat tolerance; and to calculate broad-sense heritability for carrot.

\section{Materials and Methods}

Germplasm. A total of 293 carrot genetic stocks consisting of 207 cultivated and 63 wild accessions from the USDA NPGS collection of PIs, 15 inbred lines from the USDA carrot breeding program, and eight commercial fresh market hybrids widely grown in the United States were included in this analysis. To better identify heat stress effects on germination, carrot accessions with more than $50 \%$ germination under nonstress conditions were included, as in recent evaluations of salinity tolerance (Bolton and Simon, 2019). The 293 carrot accessions originated from 41 countries and were classified into 14 regions based on their origin (Eastern Africa, Northern Africa, Southern Africa, North America, South America, Central Asia, Eastern Asia, Southern Asia, Western Asia, Eastern Europe, Northern Europe, Southern Europe, Western Europe,

Received for publication 17 Apr. 2019. Accepted for publication 30 May 2019.

We thank the Global Crop Diversity Trust Project GS14014 for providing financial support. We also thank Kathleen Reitsma and the U.S. Department of Agriculture National Germplasm System for their capable assistance in providing the plant introduction carrot collection accessions.

${ }^{1}$ These authors contributed equally to this work.

${ }^{2}$ Corresponding author. E-mail: psimon@wisc.edu. and Oceania) and they represent much of the global genetic diversity for carrot (Iorizzo et al., 2013). A subset of these accessions is also being evaluated in field trials in Bangladesh and Pakistan for heat tolerance at various stages of growth (A. Ali and M.A. Rahim, personal communication).

Determination of optimal heat tolerance evaluation temperature. A pilot experiment was conducted to determine the optimal temperature for evaluating heat tolerance in carrot. For this experiment, three widely grown commercial hybrids (coded as A, B, and C) and the cultivar Brasilia were selected to test seed germination under five temperatures (24.0, $32.5,35.0,37.5$, and $40.0{ }^{\circ} \mathrm{C}$ ). 'Brasilia' was included because it is widely grown in the warmer climate of Brazil and is known to be relatively heat tolerant, whereas the three hybrids represent cultivars bred for more temperate production areas. The temperature at which statistically most significant differences were recorded between accessions, that being the lowest $P$ value, was chosen as the optimal temperature to evaluate heat tolerance at the seed germination stage.

Germination assay. This experiment was conducted using a randomized complete block design with six replications and two treatments, that is, control $\left(24^{\circ}\right)$ and heat stress $\left(35^{\circ}\right)$. Twenty seeds from each carrot accession were placed on P5 filter paper in $60 \times 15 \mathrm{~mm}$ petri dishes (Fisher Scientific, Waltham, MA). Petri dishes were added with $7 \mathrm{~mL}$ of distilled water and were placed in complete darkness at $24 \pm 1{ }^{\circ} \mathrm{C}$ for control in plastic bins and at $35 \pm 1{ }^{\circ} \mathrm{C}$ in an incubator (Fisher Scientific) for heat stress.

Evaluation under $35^{\circ} \mathrm{C}$. Seed germination data were collected for a total of $10 \mathrm{~d}$ with measurements taken $2,4,6,8$, and 10 days after sowing. A seed was scored as germinated when the radicle had emerged and had a length of more than $1 \mathrm{~mm}$. At each measurement time, any germinated seed was removed from the petri dish. Standard criteria for determining performance of carrot accessions under heat stress included final percent germination under nonstress conditions $\left(\mathrm{PG}_{\text {Control }}\right)$, final percent germination under heat stress $\left(\mathrm{PG}_{\text {Heat }}\right), \mathrm{AD}, \mathrm{II}, \mathrm{RHT}$, and HTI, as were used to evaluate salinity tolerance in carrot (Bolton and Simon, 2019). These measurements were calculated with the following equations: $\mathrm{AD}=\mathrm{PG}_{\mathrm{Control}}-\mathrm{PG}_{\text {Heat }}$; $\mathrm{II}=100 *\left(\mathrm{PG}_{\text {Control }}-\mathrm{PG}_{\text {Heat }}\right) /\left(\mathrm{PG}_{\text {Control }}\right)$; RHT $=\mathrm{PG}_{\text {Heat }} / \mathrm{PG}_{\text {Control }} ;$ HTI $=\left(\mathrm{PG}_{\text {Heat }}\right.$ $\left.* \mathrm{PG}_{\text {Control }}\right) /\left(\mathrm{PG}_{\text {Average }}\right)^{2}$, whereas $\mathrm{PG}_{\text {Average }}$ is the average percent germination of all carrot accessions evaluated under no heat stress.

Data analysis. Statistical mixed linear models (Eq. [1]) were used for analysis of variance (ANOVA) for six measurements related to seed germination on the basis of carrot accessions, origin of carrot accessions, and heat treatments.

$$
Y_{i j}=\mu+R_{i}+A_{j}+\varepsilon_{i j},
$$

where $Y_{\mathrm{ij}}=$ the value of the measurements for the $j^{\text {th }}$ carrot accession in the $i^{\text {th }}$ replication where $i=1, \ldots, 6$, and $j=1, \ldots, 289 ; \mu=$ total mean (constant), $R_{\mathrm{i}}=$ effect of the $i^{\text {th }}$ replication (random effect) on the response measurement, $A_{\mathrm{j}}=$ effect of the $j^{\text {th }}$ accession (fixed effect) on the response measurement, and $\varepsilon_{\mathrm{ij}}=$ effect of the experimental error associated with $i j^{\text {th }}$ observation. All analyses were performed in R. 3.4.4 (R Core Team, 2018). The lmer function in the lme 4 package was used for ANOVA test (Bates et al., 2018). The mean separation analysis on the basis of region of origin of carrot accession was performed using least significant difference test function found in the agricolae package with alpha $=0.05$ (De Mendiburu, 2014). Pearson rank correlations between measurements were calculated using the cor function found in the stats package ( $\mathrm{R}$ Core Team, 2018).

The among-accession and within-accession variances were used for calculating broadsense heritability $\left(\mathrm{H}^{2}\right)$ as derived from Falconer and Mackay (1996) by using Eq. [2] below,

$$
\begin{aligned}
H^{2}= & \left(\sigma^{2} G / \sigma^{2} P\right)=\left[\sigma^{2} G /\left(\sigma^{2} G\right.\right. \\
& \left.\left.+\left(\sigma^{2} E / r\right)+\sigma^{2} R / r\right)\right],
\end{aligned}
$$

where $\sigma_{\mathrm{G}}^{2}=$ genotypic (accessions) variance, $\sigma_{\mathrm{P}}^{2}=$ phenotypic variance, $\sigma_{\mathrm{E}}^{2}=$ variance due to experimental error, $\sigma_{\mathrm{R}}^{2}=$ variance due to replication, and $r=$ the number of replications for each treatment. Variance components were derived using formulas: $\sigma^{2}{ }_{\mathrm{G}}=$ $(\mathrm{MSA}-\mathrm{MSE}) / r, \sigma_{\mathrm{E}}^{2}=\mathrm{MSE}, \sigma_{\mathrm{R}}^{2}=(\mathrm{MSR}-$ $\mathrm{MSE}) / \mathrm{n}$, with MSA = mean square accession, $\mathrm{MSE}=$ mean square error, $\mathrm{MSR}=$ mean square replication, $r=$ number of replications, and $\mathrm{n}=$ number of accessions.

\section{Results and Discussion}

Optimal temperature for evaluation of heat tolerance at germination stage. Percent seed germination for the four cultivars evaluated in a preliminary study under nonstress conditions ranged from $44.0 \%$ to $84.0 \%$, with a mean of $63.8 \%$. Increasing temperature to $32.5{ }^{\circ} \mathrm{C}$ reduced the mean percent germination to $57.2 \%$ and lowered the range from $45.0 \%$ to $80.0 \%$. At $35{ }^{\circ} \mathrm{C}$, the mean percent germination was further reduced to $33.3 \%$ and lowered the range from $4.0 \%$ to $60.0 \%$. At $37.5{ }^{\circ} \mathrm{C}$, only 'Brasilia' germinated, whereas at $40{ }^{\circ} \mathrm{C}$ no germination occurred (Fig. 1). ANOVA for percent seed germination of the four carrot cultivars displayed a highly significant treatment effect $(F=$ 154.63, $P<0.0001)$ and moderately significant accession effect $(F=4.78, P=0.0044)$ on percent seed germination (Table 1). A significant difference between accessions was observed in the control temperature $\left(24^{\circ} \mathrm{C}\right)$, whereas the most significant difference between accessions was recorded at $35{ }^{\circ} \mathrm{C}(F=13.18, P=0.0002)$, indicating that $35^{\circ} \mathrm{C}$ is an optimal temperature to screen carrot germplasm for heat tolerance at the germination stage. At $37.5^{\circ} \mathrm{C}$, only 'Brasilia' germinated, and at a low rate, whereas at $40{ }^{\circ} \mathrm{C}$ there was no seed germination (Table 2 ). 


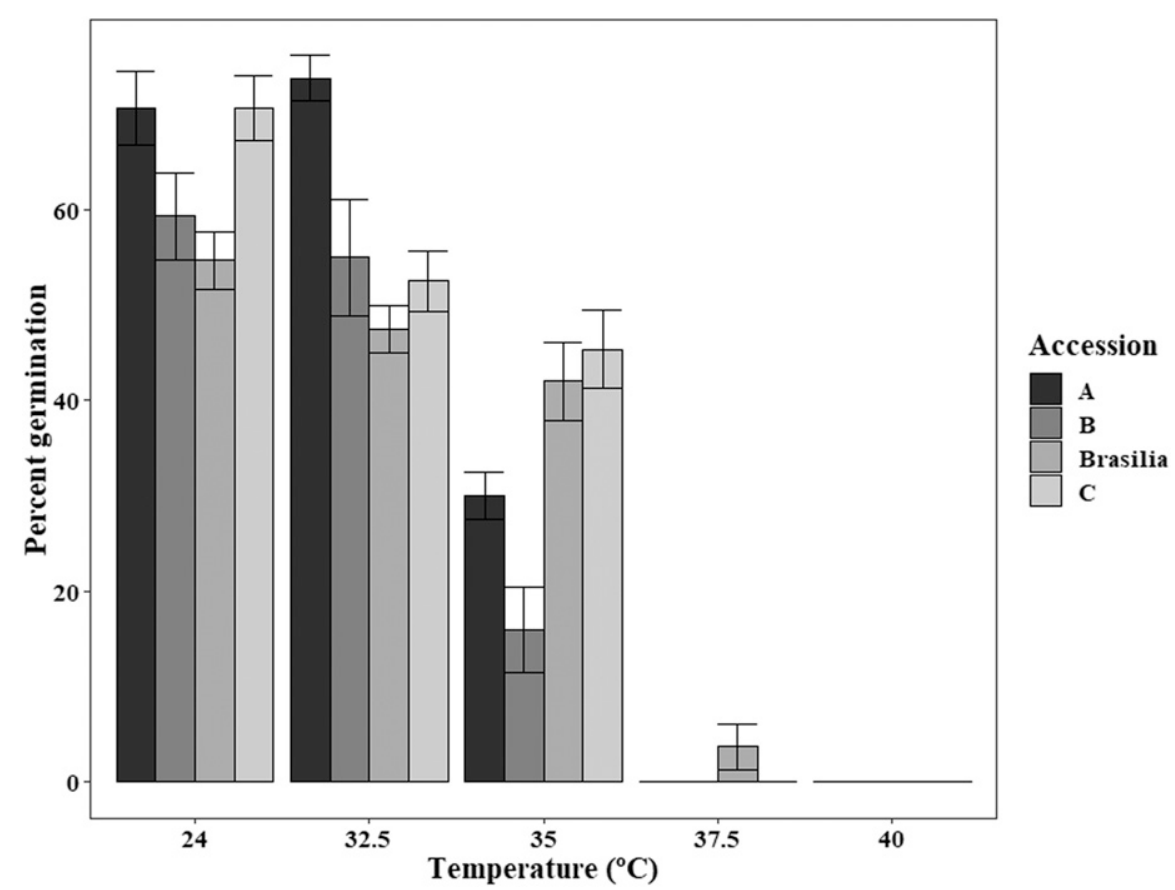

Fig. 1. Mean percent germination and standard error for three commercial hybrids (coded as A, B, and C) and the cultivar Brasilia under five different temperatures.

Table 1. Analysis of variance for pooled percent seed germination of four carrot accessions under five different temperatures.

\begin{tabular}{lrrrrc}
\hline Source & df & Sum of squares & Mean square & $F$ ratio & Prob $>F$ \\
\hline Rep & 16 & $1,050.00$ & 65.60 & 0.70 & 0.7870 \\
Treatment & 4 & $55,618.00$ & $13,904.50$ & 147.29 & $<2.2 \mathrm{E}-16$ \\
Accession & 3 & $1,523.00$ & $1,523.00$ & 5.38 & 0.0025 \\
Error & 57 & $5,383.00$ & 94.40 & & \\
\hline
\end{tabular}

The results from this experiment indicate that a temperature of $35^{\circ} \mathrm{C}$ is an optimal temperature to test for heat tolerance, which was the same temperature used by Nascimento et al. (2008).

Germination assay. The average percent germination for the 293 carrot accessions under nonstress conditions ranged from $50.0 \%$ to $100.00 \%$, with a mean of $81.6 \%$ and a standard deviation of $12.6 \%$. When seeds were tested under $35{ }^{\circ} \mathrm{C}$, the average percent germination was reduced to $59.0 \%$ with a minimum value of $0.0 \%$, a maximum of $97.5 \%$, and a standard deviation of $19.5 \%$ (Fig. 2). These results indicate that heat stress significantly reduced percent seed germination in most carrot accessions. For all traits related to heat stress, there was a significant replication effect $(P$ value $<0.0001)$ that may be attributed to variation within the incubator as reflected by the larger replication effect at $35{ }^{\circ} \mathrm{C}$ than at $24{ }^{\circ} \mathrm{C}$ (Table 3). Significant variation was recorded for the average percent germination among carrot accessions under control conditions $(F=8.35, P<$ $0.0001)$ (Table 3). PI 642756 (Netherlands), PI 643119 (France), and PI 652374 (Turkey) all had the maximum percent germination values (100.0\%), under control conditions, whereas PI 652253 (India, 50.0\%), PI 502914 (Germany, 51.1\%), and PI 652154 (Netherlands, $51.2 \%$ ) had the three lowest germina- tion values (Supplemental Table 1). Percent germination also varied significantly under heat stress among carrot accessions $(F=4.88$, $P<0.0001$ ). PI 643114 (United States, $97.5 \%$ ) had the highest percent germination value, whereas accessions PI 652208 (China), PI 652248 (Russia), PI 652400 (Turkey), and PI 652403 (Turkey) all had the second highest value $(94.2 \%)$, indicating a high level of heat tolerance. Inbred B493B had the lowest percent germination value under heat stress (0.0\%), followed by PI 652354 (Turkey, 4.2\%), B7254B (7.5\%), and PI 279764 (Syria, $10.8 \%$ ), indicating that they were especially heat sensitive.

Several of the accessions with high percent germination under heat stress were cultivated PIs from diverse geographic regions. PI 643114 (United States), PI 652400 and PI 652403 (Turkey), PI 652208 (China), and PI 652403 (Russia) all had low AD and II values $(-0.3 \%$ to $1.7 \%)$, high RHT values (0.95 to 1.0$)$ and high HTI values (1.33 to 1.45). The most heat-sensitive carrot accessions were inbred lines and wild PIs. Inbred lines B493B and B7254B, and wild PIs from Syria (PI 279764) and Turkey (PI 652354) all had a percent germination less than $5.0 \%$ under heat stress, $\mathrm{AD}$ values from $50.8 \%$ to $86.7 \%$, II values from $85.6 \%$ to $100.0 \%$, and RHT and HTI values from 0.0 to 0.14 . Surprisingly, the most tolerant accessions were not primarily from warmer regions of the world but were from very diverse geographic origins; and many tolerant accessions were cultivated varieties, suggesting that some degree of selection has occurred for heat tolerance in cultivated carrot in different parts of the world. Another interesting result was the low tolerance from several wild accessions native to regions with high levels of heat stress (Syria and Turkey), suggesting that adaptation to heat stress did not play a major role in carrot evolution and distribution based on these wild populations. In other species, sources of abiotic stress tolerance are often identified in crop wild relatives (Hajjar and Hodgkin, 2007). It appears that carrot differs from other species in this regard, as the least tolerant accessions are usually wild accessions whereas the most tolerant accessions are cultivated accessions. It should be noted that several wild carrot accessions were heat tolerant and several cultivated PIs were sensitive, contrary to general trends. That inbreds B493B and B7254B were highly sensitive was not surprising, as inbreeding depression may potentially make them more susceptible to the heat stress.

Interestingly, PI 652403 (Turkey) identified as heat tolerant in this study was also identified as one of the most salt tolerant accessions in a previous study, making this a potentially useful source of both salt and heat tolerance at the germination stage for carrot breeders (Bolton and Simon, 2019). Also, $\mathrm{B} 493 \mathrm{~B}$ had $0.0 \%$ germination under both salt stress in previous studies and heat stress in this study, indicating that this inbred line is very sensitive to two major forms of abiotic stress and can serve as a sensitive check in future studies.

$\mathrm{AD}$ in germination is a parameter used to measure heat stress $\left(\mathrm{PG}_{\text {Control }}-\mathrm{PG}_{\text {Heat }}\right)$. AD is a useful trait to identify accessions with very low tolerance to heat stress because it measures the actual reduction in germination. In this experiment, mean $\mathrm{AD}$ for all accessions evaluated was $22.6 \%$ and ranged from $-13.0 \%$ to $86.7 \%$ (Fig. $3 \mathrm{~A}$ ) with statistically significant variation observed among carrot accessions $(F=3.02, P<0.0001)$ (Table 3). PI 652154 (Netherlands, $-13.0 \%$ ) and PI 478370 (China, -12.3\%) had the lowest $\mathrm{AD}$ values, indicating heat tolerance. A total of 15 accessions had negative $\mathrm{AD}$ values, indicating that heat stress increased percent germination compared with the nonstress conditions. Accessions displaying a negative $\mathrm{AD}$ value often had a low percent germination under control temperatures and low percent germination values under heat stress close to the overall group average $(\approx 60 \%)$. These low $\mathrm{AD}$ value accessions might not be useful sources of heat tolerance for breeders, but do provide interesting material to investigate the genetic control of increased germination under heat stress. PI 652354 (Turkey, 86.7\%) and PI 515992 (Hungary, $84.2 \%$ ) had the highest AD values, indicating that heat stress greatly reduced germination and thus they were very heat sensitive. 
Table 2. Analysis of variance for seed germination of four carrot accessions under five different temperatures.

\begin{tabular}{lllrrrc}
\hline Temperature & Source & $\mathrm{df}$ & Sum of squares & Mean square & $F$ ratio & Prob $>F$ \\
\hline $24{ }^{\circ} \mathrm{C}$ & Rep & 3 & 443.33 & 88.67 & 1.08 & 0.4114 \\
& Accession & 3 & $1,186.00$ & 395.33 & 4.81 & 0.0154 \\
$32.5{ }^{\circ} \mathrm{C}$ & Error & 9 & $1,234.00$ & 82.27 & & \\
& Rep & 3 & 317.19 & 105.73 & 2.37 & 0.1384 \\
& Accession & 3 & $1,579.69$ & 526.56 & 11.80 & 0.0018 \\
$355^{\circ} \mathrm{C}$ & Error & 9 & 401.56 & 44.62 & & \\
& Rep & 3 & 589.30 & 117.87 & 1.46 & 0.2593 \\
& Accession & 3 & $3,184.00$ & $1,061.33$ & 13.18 & 0.0002 \\
$37.5{ }^{\circ} \mathrm{C}$ & Error & 9 & $1,208.00$ & 80.53 & & \\
& Rep & 3 & 17.19 & 5.73 & 1.00 & 0.4363 \\
& Accession & 3 & 42.19 & 14.06 & 2.46 & 0.1298 \\
$40{ }^{\circ} \mathrm{C}$ & Error & 9 & 51.56 & 5.73 & & \\
& Rep & 3 & 0.00 & 0.00 & & \\
& Accession & 3 & 0.00 & 0.00 & & \\
\hline & Error & 9 & 0.00 & 0.00 & &
\end{tabular}

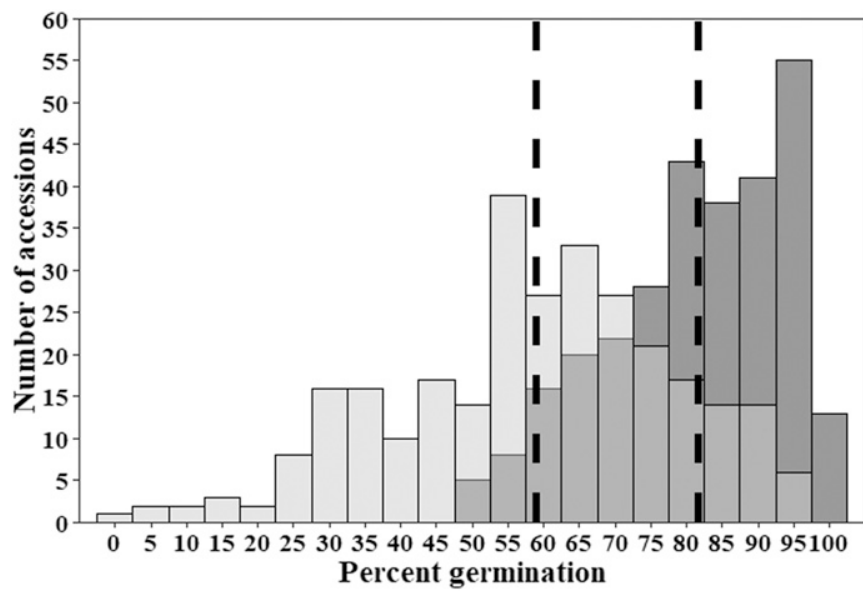

\section{Treatment \\ Without heat stress With heat stress}

Fig. 2. Distribution and mean (dotted line) percent seed germination among 293 carrot accessions without heat stress (dark gray) and with heat stress (light gray).

II $\left[\mathrm{II}=100 *\left(\mathrm{PG}_{\text {Control }}-\mathrm{PG}_{\text {Heat }}\right) / \mathrm{PG}_{\text {Control }}\right]$ values were significantly different among carrot accessions $(F=2.91, P<0.0001)$ (Table 3 ) and had a range from $35.7 \%$ to $100.0 \%$ (Fig. 3B). PI 652154 (Netherlands, $-35.7 \%)$ and PI 478370 (China, $-22.3 \%$ ) had the lowest II, agreeing with $\mathrm{AD}$ and indicating that heat stress increased germination for these accessions. B493B had a maximum II value of $100.0 \%$ followed by PI 652354 (Turkey, $95.6 \%$ ), indicating that they are highly heatsensitive accessions.

RHT $\left(\mathrm{RHT}=\mathrm{PG}_{\text {Heat }} / \mathrm{PG}_{\mathrm{Control}}\right)$ is a useful criterion for evaluating heat stress, as it gives a way to account for the percent germination under the control. RHT was also significantly different among carrot accessions $(F=8.34$, $P<0.0001$ ) (Table 3 ) with a population mean of 0.74 and a range from 0 to 1.36 (Fig. 3C). PI 652154 (Netherlands, 1.36) and PI 478370 (China, 1.22) had the highest RHT values, whereas B493B, 7254B, PI 279764 (Libya), PI 515992 (Hungary), and PI 652354 (Turkey) all had low values (0.0 to 0.14$)$. Similar to $\mathrm{AD}$, accessions with high RHT values displayed low percent germination values under control conditions and thus provide a more useful resource for understanding the genetics of performing better under heat stress rather than useful breeding material.
Heat tolerance index $\left[\mathrm{HTI}=\left(\mathrm{PG}_{\mathrm{Heat}}\right.\right.$ $\left.\left.* \mathrm{PG}_{\text {Control }}\right) /\left(\mathrm{PG}_{\text {Average }}\right)^{2}\right]$ is an important trait to consider, as it takes into account both the percent germination under heat stress and under control conditions while comparing each accession to the population average, thus giving a ranking among all accessions evaluated. An accession with a high HTI will have higher percent germination under both conditions, making it a useful accession to be selected for use in a commercial growing setting. HTI was significantly different among carrot accessions evaluation $(F=$ $7.28, P<0.0001)$ (Table 3 ) with a population mean of 0.74 and a range from 0.0 to 1.45 (Fig. 3D). PI 643114 (United States, 1.45) and PI 652208 (China, 1.4) had the highest HTI, suggesting that they were highly heat tolerant and had high percent germination under nonstress conditions, whereas inbred lines B493B and B7254B, along with PI 652354 (Turkey), had the lowest HTI values (0.0-0.06).

The accessions used in this study demonstrate a wide range of phenotypic variation for each of the heat stress parameters measured. Exposure to $35{ }^{\circ} \mathrm{C}$ significantly reduced germination for most of the carrot diversity panel, agreeing with an earlier study (Nascimento et al., 2008). This evaluation reports a similar range of variation for heat tolerance as Nascimento et al. (2008), and evaluated nearly three times additional carrot accessions, including a broad range of cultivated open pollinated varieties. There were differences between these two evaluations for the four overlapping accessions ('Brasilia', PI 261782, PI 285613, and PI 537093) that may be attributed to differences in the seed lot and/or the number of replications that were used. These results suggest the value of evaluating a large number of diverse carrot accessions for heat stress, as has been suggested for salt stress in carrot (Bolton and Simon, 2019).

Heat tolerance according to geographic origin. Significant differences were observed for seed germination under control conditions and for all heat germination parameters among the 14 different geographic origins of carrot accessions $(P$ values $<0.0001)$ (Table 4). When comparing cultivated, wild, inbred, and hybrid accessions, accessions from Eastern and Central Asia demonstrated an average higher heat tolerance at the germination stage. Accessions from Eastern Asia had a mean $\mathrm{AD}$ of $13.96 \%$ and a range from $-12.3 \%$ to $36.8 \%$, a mean II of 14.5 , and a range from $-22.3 \%$ to $39.1 \%$, a mean RHT of 0.86 and a range from 0.61 to 1.22 , and a mean HTI of 0.82 , and a range from 0.26 to 1.40. Accessions from Central Asia had similar values and ranges to those from Eastern Asia with a mean AD of $13.7 \%$ and a range from $-5.0 \%$ to $30.5 \%$, a mean II of $15.4 \%$ and a range from $-17.8 \%$ to $44.1 \%$, a mean RHT of 0.85 and a range from 0.56 to 1.17 , and a mean HTI of 0.83 and a range from 0.29 to 1.38. Accessions from Eastern Africa and Southern Europe only included one and six accessions, respectively, but were among the most heat sensitive, having RHT and HTI values of 0.52 or lower along with $\mathrm{AD}$ and II values $(41.4 \%$ to $50.6 \%$ ) (Table 5 ). Although accessions from Central and Eastern Asia were on average more heat tolerant, it is important to note the wide range of phenotypic variation within a single region and thus the need to evaluate multiple accessions from within a region when possible.

Heat tolerance according to domestication status and root color. No significant difference was observed for mean percent germination under nonstress conditions in comparing cultivated PIs $(82.0 \%)$, wild PIs $(80.2 \%)$, and inbred lines $(78.4 \%)$ (Table 6$)$. Under heat stress, cultivated PIs demonstrated a significantly higher tolerance than the wild PIs and inbred lines, with a mean percent germination under heat of $64.3 \%$ and a range from $12.5 \%$ to $97.5 \%$, a mean AD of $17.7 \%$, mean II of $20.0 \%$, mean RHT of 0.80 , and mean HTI of 0.81 . An important observation to note is that most wild PIs originated from Western Asia (Table 7) and the inbred lines are exclusively from the USDA breeding program, potentially accounting for the trends we observed. No significant difference in heat tolerance was observed between the wild PIs and inbred lines for all traits, and most accessions from 
Table 3. Analysis of variance for six measurements related to seed germination among 293 carrot accessions.

\begin{tabular}{|c|c|c|c|c|c|c|}
\hline Measurement & Source & df & Sum of squares & Mean square & $F$ ratio & Prob $>F$ \\
\hline \multirow[t]{3}{*}{ Germination without heat stress } & Rep & 5 & 218.00 & 43.61 & 0.40 & 0.8565 \\
\hline & Accession & 288 & $269,354.00$ & 935.26 & 8.35 & $<2.0 \mathrm{E}-16$ \\
\hline & Error & 1,440 & $161,326.00$ & 112.03 & & \\
\hline \multirow[t]{3}{*}{ Germination with heat stress } & Rep & 5 & $24,955.00$ & $4,990.90$ & 10.66 & $4.5 \mathrm{E}-10$ \\
\hline & Accession & 288 & $658,715.00$ & $2,287.20$ & 4.88 & $<2.2 \mathrm{E}-16$ \\
\hline & Error & 1,440 & $674,325.00$ & 468.30 & & \\
\hline \multirow[t]{3}{*}{ Absolute decrease (AD) } & Rep & 5 & $22,563.00$ & $4,512.70$ & 7.71 & $3.6 \mathrm{E}-07$ \\
\hline & Accession & 288 & $509,434.00$ & $1,768.90$ & 3.02 & $<2.2 \mathrm{E}-16$ \\
\hline & Error & 1,440 & $842,581.00$ & 585.10 & & \\
\hline \multirow[t]{3}{*}{ Inhibition index (II) } & Rep & 5 & $40,590.00$ & 818.10 & 8.34 & 8.7E-08 \\
\hline & Accession & 288 & $816,629.00$ & $2,835.50$ & 2.91 & $<2.2 \mathrm{E}-16$ \\
\hline & Error & 1,440 & $1,401,611.00$ & 973.30 & & \\
\hline \multirow[t]{3}{*}{ Relative heat tolerance (RHT) } & Rep & 5 & 4.06 & 0.81 & 8.34 & 8.7E-08 \\
\hline & Accession & 288 & 81.66 & 0.28 & 2.91 & $<2.2 \mathrm{E}-16$ \\
\hline & Error & 1,440 & 140.16 & 0.10 & & \\
\hline \multirow[t]{3}{*}{ Heat tolerance index (HTI) } & Rep & 5 & 4.38 & 0.88 & 10.78 & $3.4 \mathrm{E}-10$ \\
\hline & Accession & 288 & 170.32 & 0.59 & 7.28 & $<2.2 \mathrm{E}-16$ \\
\hline & Error & 1,440 & 116.94 & 0.08 & & \\
\hline
\end{tabular}
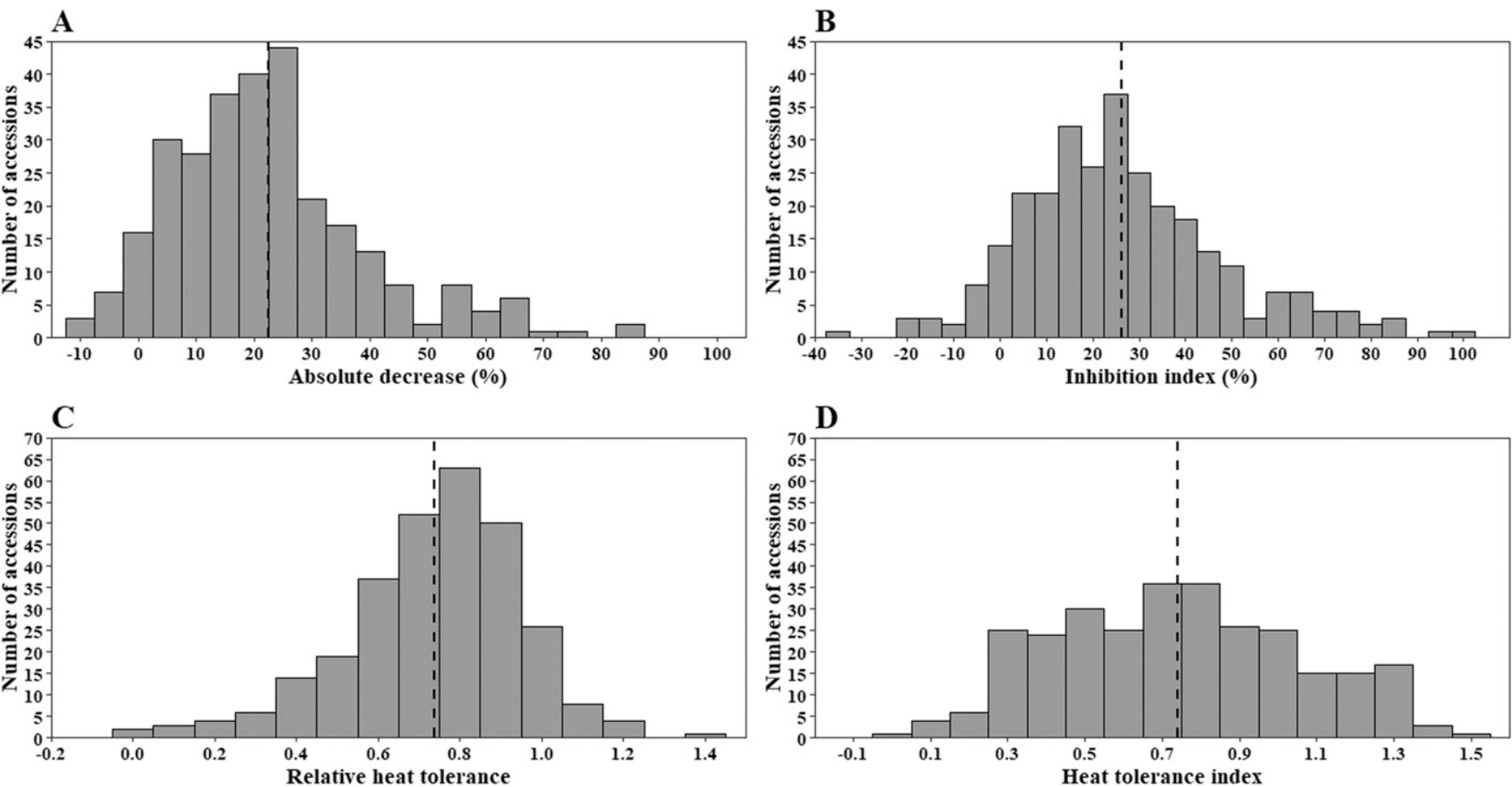

Fig. 3. Distribution and mean (dotted line) among 293 carrot accessions with four different measures of heat tolerance: (A) absolute decrease, (B) inhibition index, (C) relative heat tolerance, and (D) heat tolerance index.

these groups demonstrated higher sensitivity to heat stress than the cultivated accessions. There were some exceptions to the general trends based on domestication status. Inbred lines B5208B and Nb4002B both had moderately high HTI values of 0.95 and 0.93 , respectively, whereas Ames 30259 (Tunisia) and PI 269487 (Pakistan), two wild PIs, have HTI values of 1.03 and 1.17 , respectively. There were also many cultivated PIs with low levels of heat tolerance, such as PI 234621 (South Africa) and PI 515992 (Hungary), both of which have less than $25.0 \%$ germination under heat stress conditions.

Heat stress tolerance trait means of cultivated carrots did not vary according to root color under nonstress conditions. Under heat stress conditions, there was no significant difference among the white, orange, yellow, and red accessions with a range from $62.7 \%$ to $66.4 \%$ germination under heat stress and HTI range from 0.76 to 0.84 . Purple rooted carrots were significantly more sensitive than the other colors, with a $55.1 \%$ germination under heat stress, down from $74.0 \%$ at $24{ }^{\circ} \mathrm{C}$, and HTI of 0.62 (Table 6). It is important to note that the number of samples for each color category were not equal and were not equally distributed across geographic origins, thus the trends reported here should be confirmed with larger sample sizes.

Broad-sense heritability. A high broadsense heritability $\left(\mathrm{H}^{2}\right)$ was observed for germination under nonstress conditions $\left(\mathrm{H}^{2}=0.88\right)$, for germination under heat stress $\left(\mathrm{H}^{2}=0.79\right)$, and for HTI $\left(\mathrm{H}^{2}=0.86\right)$, indicating a significant genetic basis for these traits. Heritability values for $\mathrm{AD}\left(\mathrm{H}^{2}=0.66\right)$, II $\left(\mathrm{H}^{2}=0.66\right)$, and RHT $\left(\mathrm{H}^{2}=0.64\right)$ all were moderately high, suggesting a genetic basis for these traits. Interestingly, the heritability values for heat stress germination were lower than that observed in the same set of accessions for salt stress germination (Bolton and Simon, 2019). These differences in heritability suggest that either there is a smaller genetic component for heat tolerance germination in carrot, a larger environmental component that accounts for the phenotypic variation, or that it is a more genetically complex trait than salt tolerance germination with multiple genes responsible for the phenotype. These genetic factors warrant further investigation with the goal of identifying significant quantitative trait loci associated with heat tolerance at the germination stage. 
Table 4. Analysis of variance for six measurements related to seed germination among carrot accessions from 14 geographic regions of origin.

\begin{tabular}{|c|c|c|c|c|c|c|}
\hline Measurement & Source & $\mathrm{df}$ & Sum of squares & Mean square & $F$ ratio & Prob $>F$ \\
\hline \multirow[t]{3}{*}{ Germination without heat stress } & Rep & 5 & 218.00 & 43.61 & 0.18 & 0.97 \\
\hline & Region & 13 & $17,618.00$ & $1,355.22$ & 5.63 & $3.64 \mathrm{E}-10$ \\
\hline & Error & 1,715 & $413,062.00$ & 240.85 & & \\
\hline \multirow[t]{3}{*}{ Germination with heat stress } & Rep & 5 & $24,955.00$ & $4,990.90$ & 6.79 & $2.83 \mathrm{E}-06$ \\
\hline & Region & 13 & $71,584.00$ & $5,506.50$ & 7.49 & $1.56 \mathrm{E}-14$ \\
\hline & Error & 1,715 & $1,261,455.00$ & 735.50 & & \\
\hline \multirow[t]{3}{*}{ Absolute decrease (AD) } & Rep & 5 & $22,563.00$ & $4,512.70$ & 6.10 & $1.32 \mathrm{E}-05$ \\
\hline & Region & 13 & $83,612.00$ & $6,431.77$ & $8,370.00$ & $<2.2 \mathrm{E}-16$ \\
\hline & Error & 1,715 & $1,268,404.00$ & 739.60 & & \\
\hline \multirow[t]{3}{*}{ Inhibition index (II) } & Rep & 5 & $40,590.00$ & $8,118.10$ & 6.64 & $3.94 \mathrm{E}-06$ \\
\hline & Region & 13 & $120,634.00$ & $9,279.50$ & 7.59 & $8.99 \mathrm{E}-15$ \\
\hline & Error & 1,715 & $2,097,606.00$ & $1,223.10$ & & \\
\hline \multirow[t]{3}{*}{ Relative heat tolerance (RHT) } & Rep & 5 & 4.06 & 0.82 & 6.64 & $3.94 \mathrm{E}-06$ \\
\hline & Region & 13 & 12.06 & 0.93 & 7.59 & $8.99 \mathrm{E}-15$ \\
\hline & Error & 1,715 & 209.76 & 0.12 & & \\
\hline \multirow[t]{3}{*}{ Heat tolerance index (HTI) } & Rep & 5 & 4.38 & 0.88 & 5.51 & 4.92E-05 \\
\hline & Region & 13 & 14.56 & 1.12 & 7.05 & $1.74 \mathrm{E}-13$ \\
\hline & Error & 1,715 & 272.70 & 0.16 & & \\
\hline
\end{tabular}

Table 5. Mean separation for relative heat tolerance (RHT), heat tolerance index (HTI), absolute decrease (AD), and inhibition index (II) across 14 geographic regions of origin for all 293 accessions [63 wild plant introductions (PIs), 207 cultivated PIs, 15 inbreds, and 8 hybrids].

\begin{tabular}{|c|c|c|c|c|c|c|c|c|c|}
\hline \multirow{2}{*}{$\begin{array}{l}\text { Region of origin } \\
\text { Eastern Asia }\end{array}$} & \multirow{2}{*}{$\frac{\text { Accessions }}{31}$} & \multicolumn{2}{|c|}{ RHT } & \multicolumn{2}{|c|}{ HTI } & \multicolumn{2}{|c|}{$\mathrm{AD}(\%)$} & \multicolumn{2}{|c|}{ II (\%) } \\
\hline & & 0.86 & $\mathrm{~A}^{\mathrm{z}}$ & 0.82 & $\mathrm{AB}$ & 13.96 & $\mathrm{AC}$ & 14.52 & $\mathrm{AC}$ \\
\hline Central Asia & 18 & 0.85 & $\mathrm{AB}$ & 0.83 & $\mathrm{AB}$ & 13.66 & $\mathrm{AC}$ & 15.36 & $\mathrm{ABC}$ \\
\hline Southern Asia & 46 & 0.80 & $\mathrm{ABC}$ & 0.72 & $\mathrm{BC}$ & 16.18 & $\mathrm{AC}$ & 20.20 & $\mathrm{ABC}$ \\
\hline Eastern Europe & 20 & 0.79 & $\mathrm{ABC}$ & 0.82 & $\mathrm{AB}$ & 20.06 & $\mathrm{ABC}$ & 21.55 & $\mathrm{ABC}$ \\
\hline Northern Europe & 14 & 0.76 & $\mathrm{ABC}$ & 0.74 & $\mathrm{ABC}$ & 20.41 & $\mathrm{ABC}$ & 23.94 & $\mathrm{ABC}$ \\
\hline Western Europe & 40 & 0.75 & $\mathrm{BC}$ & 0.76 & $\mathrm{ABC}$ & 21.84 & $\mathrm{ABC}$ & 25.32 & $\mathrm{ABC}$ \\
\hline North America & 42 & 0.70 & $\mathrm{CD}$ & 0.86 & A & 25.19 & $\mathrm{ABC}$ & 29.65 & $\mathrm{ABC}$ \\
\hline North Africa & 8 & 0.70 & CDE & 0.65 & $\mathrm{BC}$ & 26.14 & $\mathrm{ABC}$ & 30.14 & $\mathrm{ABC}$ \\
\hline Oceania & 1 & 0.68 & $\mathrm{CDE}$ & 0.60 & $\mathrm{C}$ & 25.72 & $\mathrm{ABC}$ & 32.26 & $\mathrm{ABC}$ \\
\hline South America & 2 & 0.64 & $\mathrm{CDE}$ & 0.80 & $\mathrm{ABC}$ & 33.29 & $\mathrm{ABC}$ & 35.93 & $\mathrm{ABC}$ \\
\hline Western Asia & 61 & 0.63 & $\mathrm{DE}$ & 0.63 & $\mathrm{C}$ & 31.19 & $\mathrm{ABC}$ & 36.73 & $\mathrm{AB}$ \\
\hline South Africa & 3 & 0.61 & $\mathrm{DE}$ & 0.63 & $\mathrm{BC}$ & 36.14 & $\mathrm{AB}$ & 39.41 & $\mathrm{AB}$ \\
\hline Southern Europe & 6 & 0.52 & $\mathrm{E}$ & 0.48 & $\mathrm{C}$ & 41.17 & A & 48.45 & A \\
\hline Eastern Africa & 1 & 0.49 & $\mathrm{E}$ & 0.46 & $\mathrm{C}$ & 44.17 & A & 50.61 & A \\
\hline
\end{tabular}

${ }^{\mathrm{z}}$ Means with the same letter are not significantly different using Fisher's least significant difference test at alpha $=0.05$.

Table 6. Mean ( $\pm \mathrm{SE}$ ), for percent germination without heat stress (Nonstress), percent germination with $35{ }^{\circ} \mathrm{C}$ heat stress $(\mathrm{Stress})$, absolute decrease $(\mathrm{AD})$, inhibition index (II), relative heat tolerance (RHT), and heat tolerance index (HTI) separated by domestication status (DS) and primary root color (RC) [excluding wild plant introductions (PIs)] with number of accessions found in each category.

\begin{tabular}{|c|c|c|c|c|c|c|c|c|c|c|c|c|c|c|}
\hline Factor & Category & Accessions & Nonstress & & Stress & & $\mathrm{AD}$ & & II & & RHT & & HTI & \\
\hline \multirow[t]{3}{*}{$\overline{\mathrm{DS}}$} & Cultivated PI & 206 & $82.0 \pm 0.9$ & $\mathrm{~A}^{\mathrm{z}}$ & $64.3 \pm 1.2$ & $\mathrm{~A}$ & $17.7 \pm 1.0$ & $\mathrm{~A}$ & $20.0 \pm 1.2$ & $\mathrm{~A}$ & $0.80 \pm 0.01$ & $\mathrm{~A}$ & $0.81 \pm 0.02$ & $\mathrm{~A}$ \\
\hline & Wild PI & 63 & $80.2 \pm 1.2$ & A & $44.5 \pm 2.3$ & B & $35.8 \pm 2.4$ & B & $42.8 \pm 2.9$ & B & $0.57 \pm 0.03$ & B & $0.53 \pm 0.03$ & B \\
\hline & Inbred & 15 & $78.4 \pm 3.5$ & A & $41.7 \pm 5.3$ & B & $36.6 \pm 4.3$ & B & $46.5 \pm 6.6$ & B & $0.54 \pm 0.07$ & B & $0.52 \pm 0.07$ & B \\
\hline \multirow[t]{5}{*}{$\mathrm{RC}$} & White & 5 & $84.5 \pm 6.7$ & A & $62.7 \pm 12.0$ & $\mathrm{AB}$ & $21.8 \pm 7.3$ & A & $25.3 \pm 8.2$ & A & $0.75 \pm 0.08$ & A & $0.83 \pm 0.21$ & $\mathrm{AB}$ \\
\hline & Orange & 153 & $83.0 \pm 1.1$ & $\mathrm{~A}$ & $62.8 \pm 1.5$ & $\mathrm{AB}$ & $20.2 \pm 1.2$ & A & $23.4 \pm 1.6$ & A & $0.76 \pm 0.02$ & A & $0.81 \pm 0.03$ & $\mathrm{AB}$ \\
\hline & Yellow & 38 & $82.2 \pm 1.8$ & A & $66.4 \pm 2.3$ & A & $15.8 \pm 1.5$ & A & $17.7 \pm 2.0$ & A & $0.82 \pm 0.02$ & A & $0.84 \pm 0.04$ & A \\
\hline & Red & 9 & $76.8 \pm 5.0$ & $\mathrm{AB}$ & $64.6 \pm 4.0$ & $\mathrm{AB}$ & $12.2 \pm 4.1$ & $\mathrm{~A}$ & $10.8 \pm 4.9$ & A & $0.89 \pm 0.05$ & A & $0.76 \pm 0.09$ & $\mathrm{AB}$ \\
\hline & Purple & 19 & $74.0 \pm 3.1$ & $\mathrm{AB}$ & $55.1 \pm 3.6$ & B & $18.8 \pm 3.9$ & A & $22.3 \pm 5.2$ & A & $0.78 \pm 0.05$ & A & $0.62 \pm 0.06$ & B \\
\hline
\end{tabular}

${ }^{\mathrm{z}}$ Means with the same letter are not significantly different using Fisher's least significant difference test at alpha $=0.05$.

Table 7. Correlation among seven heat stress parameters: absolute decrease (AD), hundred seed weight (HSW), inhibition index (II), under nonstressed condition (Nonstress), relative heat tolerance (RHT), heat tolerance index (HTI), and under heat stress (Stress).

\begin{tabular}{|c|c|c|c|c|c|c|c|}
\hline Parameter & Nonstress & Stress & RHT & $\mathrm{AD}$ & II & HTI & HSW \\
\hline Nonstress & 1 & & & & & & \\
\hline Stress & 0.50 & 1 & & & & & \\
\hline RHT & -0.04 & 0.83 & 1 & & & & \\
\hline $\mathrm{AD}$ & 0.16 & -0.78 & -0.97 & 1 & & & \\
\hline II & 0.04 & -0.83 & -1.00 & 0.97 & 1 & & \\
\hline HTI & 0.72 & 0.95 & 0.62 & -0.56 & -0.62 & 1 & \\
\hline HSW & -0.20 & 0.00 & 0.13 & -0.15 & -0.13 & -0.17 & 1 \\
\hline
\end{tabular}

Correlation among heat tolerance parameters, seed weight, and salt tolerance. Pearson correlation coefficients calculated for each of the heat tolerance parameters along with hundred seed weight (HSW) of each accession (Table 7) indicated that germination under nonstress conditions was highly correlated to the HTI $(r=0.74)$, but the correlation with germination under heat stress conditions $(r=0.50)$ was lower. Germination without stress was not strongly correlated to the other parameters evaluated $(r=-0.20$ to 0.16$)$. These results indicate that percent germination under nonstress conditions does not predict heat tolerance germination in carrot. HSW had no correlation with percent germination under heat stress $(r=$ 0.00 ) and a very weak negative correlation with germination under nonstress conditions $(r=-0.20)$. These results were similar to those observed for salt tolerance germination where nonstress germination was also correlated with salt tolerance index (STI) $(r=$ $0.54)$ and with stress salt stress $(r=0.40)$. Germination under salt stress was slightly 
more correlated with HSW than germination under heat stress (Bolton and Simon, 2019). These data suggest that heat tolerance parameters and salt tolerance parameters follow similar trends, with heat tolerance having slightly stronger correlations among those parameters. Pearson correlation between HTI and the STI values calculated in Bolton and Simon (2019) display a strong correlation (0.69) between the two traits, suggesting that many of the accessions tolerant to one stress are also tolerant to the other. These results are not surprising, as heat stress and salt stress have similar effects on seed physiology and often cause similar stress responses. Although not evaluated in this study, it will be interesting to compare heat tolerance of these accessions in the field to heat tolerance at the seed germination stage and to determine if there is any correlation between the two studies.

\section{Conclusions}

This study identified a wide range of phenotypic variation for heat tolerance at the germination stage in a diverse collection of carrot germplasm. Five cultivated carrot accessions representing four countries (PI 643114, United States; PI 652208, China; PI 652248, Russia; and PIs 652400 and 654203, Turkey) were identified as the most heat-tolerant accessions, whereas inbred lines B493B and B7254B, along with wild accessions PI 279764 (Libya) and PI 652354 (Turkey) were identified as heat-sensitive accessions. The wide geographic range from which all the tolerant accessions originated was particularly surprising, as it suggests that heat tolerance has been under selection in multiple regions of the world where carrot is cultivated. This study adds to the current body of research for heat tolerance in carrot seed germination by identifying an optimal temperature for screening and measuring a high heritability of tolerance in a large collection of germplasm from diverse global regions. HTI was confirmed to be a particularly important measure of tolerance. This evaluation, coupled with recent evaluations of salt tolerance in the same diverse germplasm, provides valuable information for future studies of abiotic stress in carrot.

\section{Literature Cited}

Bano, S., M. Ashraf, and N.A. Akram. 2014. Salt stress regulates enzymatic and nonenzymatic antioxidative defense system in the edible part of carrot [Daucus carota (L.)]. J. Plant Interact. 9(1):324-329.

Balla, K., S. Karsai, S. Benzce, and O. Veisz. 2012. Germination ability and seedling vigour in the progeny of heat-stressed wheat plants. Acta Agron. Hung. 60(4):299-308.

Bates, D., M. Maechler, B. Bolker, S. Walker, R.H.B. Christensen, H. Singmann, B. Dai, F Scheipl, G. Grothendieck, and P. Green. 2018. Linear mixed-effects models using 'Eigen' and S4. R. package, version 17, p. 42-44.

Bolton, A.L. and P.W. Simon. 2019. Variation for salinity tolerance during seed germination in diverse carrot [Daucus carota (L.)] germplasm. HortScience 54:38-44.

Corbineau, F., M.A. Picard, and D. Come. 1994. Effects of temperature, oxygen and osmotic pressure on germination of carrot seeds: Evaluation of seed quality. Acta Hort. 354:9-16.

De Mendiburu, F. 2014. Agricolae: Statistical procedures for agricultural research. $\mathrm{R}$ package version 1, p. 1-6.

Fahad, A., A.A. Bajwa, U. Nazir, S.A. Anjum, A. Farooq, A. Zohaib, S. Sadia, W. Nasim, S. Adkins, and S. Saud. 2017. Crop production under drought and heat stress: Plant responses and management options. Front. Plant Sci. 8:1147.

Falconer, D.S. and T.F.C. Mackay. 1996. Introduction to quantitative genetics. $4^{\text {th }}$ ed. Pearson, Essex, England.

FAO. 2017. FAOSTAT production crops. 29 Nov. 2017. <http://www.fao.org/faostat/en/\#data/QC>.

Farooq, M., H. Bramley, J.A. Palta, and K.H. Siddique. 2011. Heat stress in wheat during reproductive and grain-filling phases. Crit. Rev. Plant Sci. 30(6):491-507.

Graham, R., D. Senadhira, S. Beebe, C. Inglesias, and I. Monasterio. 1999. Breeding for micronutrient density in edible portions of stable food crops: Conventional approaches. Field Crops Res. 60(1-2):57-80.

Hajjar, R. and T. Hodgkin. 2007. The use of wild relatives in crop improvement: A survey of developments over the last 20 years. Euphytica 156(1-2):1-13.

Hasanuzzaman, M., K. Nahar, M.M. Alam, R. Roychowdhury, and M. Fujita. 2013. Physiological, biochemical, and molecular mechanisms of heat stress tolerance in plants. Int. J. Mol. Sci. 14(5):9643-9684.

Hum-Musser, S.M., T.E. Morelock, and J.B. Murphy. 1999. Relation of heat-shock proteins to thermotolerance during spinach seed germination, p. 103-105. In: J.R. Clark and M.D. Richardson (eds.). Horticultural Studies - 1998. Ark. Agr. Exp. Sta. Res. Ser. 466.

Iloh, A.C., G. Omatta, G.H. Ogbadu, and P.C. Onyenekwe. 2014. Effect of elevated temperature on seed germination and seedling growth on three cereal crops in Nigeria. Sci. Res. Essays 9(18):806-813.

Iorizzo, M., D.A. Senalik, S.L. Ellison, D. Grzebelus, P.F. Cavagnaro, C. Allender, J. Brunet, D.M. Spooner, A.V. Deynze, and P.W. Simon. 2013. Genetic structure and domestication of carrot (Daucus carota subsp. sativus) (Apiaceae). Amer. J. Bot. 100(5):930-938.

IPCC (Intergovernmental Panel on Climate Change). 2013. Climate change 2013: The physical sci- ence basis. Working Group I contribution to the IPCC Fifth Assessment Report. Cambridge University Press, Cambridge, United Kingdom. $<$ www.ipcc.ch/report/ar5/wg1 $>$.

Kahouli, B., Z. Borgi, and C. Hannachi. 2014. Effect of sodium chloride on the germination of the seeds of a collection of carrot accessions (Daucus carota L.) cultivated in the region of Sidi Bouzid. J. Stress Physiol. Biochem. 10(3):28-36.

Landjeva, S., K. Neumann, U. Lohwasser, and A. Börner. 2008. Molecular mapping of genomic regions associated with wheat seedling growth under osmotic stress. Biol. Plant. 52(2):259 266.

Mahmood, I., S. Hassan, A. Bashir, M. Qasim, and N. Ahmad. 2017. Profitability analysis of carrot production in selected districts of Punjab, Pakistan: An empirical investigation. J. App. Environ. Biol. Sci. 7:188-193.

Nascimento, W.M., J.V. Vieira, G.O. Silva, K.R. Reitsma, and D.J. Cantliffe. 2008. Carrot seed germination at high temperature: Effect of genotype and association with ethylene production. HortScience 43:1538-1543.

Nascimento, W.M. and R.S. Pereira. 2007. Preventing thermo-inhibition in carrot by seed priming. Seed Sci. Technol. 35:503-506.

Pereira, R.S., W.M. Nascimento, and J.V. Vieira. 2007. Germinação e vigor de sementes de cenoura sob condições de altas temperaturas. Hortic. Bras. 25:215-219.

R Core Team. 2018. R: A language and environment for statistical computing. R Foundation for Statistical Computing, Vienna, Austria.

Riley, G.J. 1981. Effects of high temperature on the germination of maize (Zea mays L.). Planta 151(1):68-74

Rohde, R., R.A. Muller, R. Jacobsen, E. Muller, S. Perlmutter, A. Rosenfeld, and C. Wickham. 2013. A new estimate of the average Earth surface land temperature spanning 1753 to 2011. Geoinfo. Geostat. Overview 1(1):1-7.

Rosenfeld, H.J. 2004. Sensory, chemical and morphological changes in carrots (Daucus carota L.) as influenced by climatic factors. Agricultural University of Norway, Department of Plant and Environmental Sciences, Ås.

Senthil-Kumar, M., K. Ganesh, V. Srikanthbabu, and M. Udayakumar. 2007. Assessment of variability in acquired thermotolerance: Potential option to study genotypic response and the relevance of stress genes. J. Plant Physiol. 164:111-125.

Shah, F., J. Huang, L. Cui, K. Nie, T. Shah, C. Chen, and K. Wang. 2011. Impact of hightemperature stress on rice plant and its traits related to tolerance. J. Agr. Sci. 149:545-556.

Sleimi, N., I. Bankaji, H. Touchan, and F. Corbineau. 2013. Effect of temperature and water stresses on germination of some varieties of chickpea (Cicer arietinum). Afr. J. Biotechnol. 12(17):2201-2206.

Tanumihardjo, S.A. 2012. Carotenoids and human health. Springer, New York.

Vieira, J.V., C.D. Cruz, W.M. Nascimento, and J.E.C. Miranda. 2005. Seleção de progênies de meio-irmãos de cenoura baseada em características de sementes. Hort. Bras. 23:44-47. 
Supplemental Table 1. Carrot accession, root color, country of origin, domestication status (DS), mean percent germination without heat stress (Nonstress) \pm sE, mean percent germination with $35^{\circ} \mathrm{C}$ heat stress (Stress) $\pm \mathrm{SE}$, mean absolute decrease (AD), mean inhibition index (II), relative heat tolerance (RHT), mean heat tolerance index (HTI), hundred seed weight (HSW), and rank based on HTI.

\begin{tabular}{|c|c|c|c|c|c|c|c|c|c|c|c|}
\hline Merged & Root Color & Country & DS & Nonstress $(\%)$ & Stress $(\%)$ & $\mathrm{AD}(\%)$ & II $(\%)$ & RHT & HTI & HSW & Rank \\
\hline Ames 25040 & Red-Purple & India & Cultivated $\mathrm{PI}^{\mathrm{z}}$ & $74.2 \pm 2.4$ & $49.2 \pm 10.1$ & 25.0 & 34.7 & 0.65 & 0.56 & 0.18 & 196 \\
\hline Ames 25732* & White & Syria & Wild PI & $71.9 \pm 7.4$ & $35.8 \pm 8.1$ & 36.0 & 49.8 & 0.50 & 0.41 & 0.11 & 240 \\
\hline Ames $25773 *$ & White & Syria & Wild PI & $85.8 \pm 3.3$ & $60.6 \pm 5.4$ & 25.2 & 29.7 & 0.70 & 0.79 & 0.09 & 124 \\
\hline Ames 26382* & White & Portugal & Wild PI & $63.3 \pm 7.7$ & $17.1 \pm 6.7$ & 46.2 & 60.8 & 0.39 & 0.13 & 0.13 & 285 \\
\hline Ames 26383* & White & Portugal & Wild PI & $90.8 \pm 2.4$ & $25.8 \pm 8.6$ & 65.0 & 71.9 & 0.28 & 0.36 & 0.15 & 251 \\
\hline Ames 26384* & White & Portugal & Wild PI & $88.3 \pm 4.8$ & $70.8 \pm 9.7$ & 17.5 & 19.0 & 0.81 & 0.95 & 0.15 & 77 \\
\hline Ames 27396* & White & Uzbekistan & Wild PI & $75.2 \pm 7.3$ & $44.7 \pm 13.9$ & 30.5 & 44.1 & 0.56 & 0.55 & 0.08 & 197 \\
\hline Ames 27397* & White & Uzbekistan & Wild PI & $72.8 \pm 5.1$ & $71.7 \pm 5.3$ & 1.1 & 0.1 & 1.00 & 0.79 & 0.08 & 125 \\
\hline Ames 27398 & Orange & Uzbekistan & Cultivated PI & $62.5 \pm 4.0$ & $55.8 \pm 7.7$ & 6.7 & 9.9 & 0.90 & 0.53 & 0.12 & 204 \\
\hline Ames 27399 & Yellow & Uzbekistan & Cultivated PI & $89.2 \pm 3.0$ & $88.3 \pm 5.3$ & 0.8 & -0.2 & 1.00 & 1.18 & 0.11 & 30 \\
\hline Ames $27400^{*}$ & Yellow & Uzbekistan & Cultivated PI & $85.8 \pm 3.3$ & $90.0 \pm 2.6$ & -4.2 & -5.4 & 1.05 & 1.16 & 0.15 & 34 \\
\hline Ames 29084* & Orange & Tunisia & Cultivated PI & $77.5 \pm 5.6$ & $64.2 \pm 10.4$ & 13.3 & 15.1 & 0.85 & 0.74 & 0.25 & 140 \\
\hline Ames 29087* & White & Tunisia & Wild PI & $89.3 \pm 3.9$ & $43.5 \pm 9.1$ & 45.8 & 51.2 & 0.49 & 0.59 & 0.14 & 191 \\
\hline Ames 30198* & White & Tunisia & Wild PI & $64.7 \pm 5.0$ & $63.3 \pm 7.2$ & 1.4 & -1.9 & 1.02 & 0.61 & 0.20 & 183 \\
\hline Ames 30259* & White & Tunisia & Wild PI & $90.8 \pm 2.4$ & $75.6 \pm 6.0$ & 15.3 & 16.4 & 0.84 & 1.03 & 0.08 & 55 \\
\hline Ames 30276 & Orange & Tunisia & Cultivated PI & $84.2 \pm 3.8$ & $46.7 \pm 5.1$ & 37.5 & 44.0 & 0.56 & 0.59 & 0.20 & 192 \\
\hline Ames 31193* & White & France & Wild PI & $78.3 \pm 4.4$ & $55.8 \pm 11.7$ & 22.5 & 27.2 & 0.73 & 0.66 & 0.09 & 169 \\
\hline PI 163234 & Yellow & India & Cultivated PI & $58.0 \pm 9.6$ & $35.0 \pm 9.9$ & 23.0 & 29.4 & 0.71 & 0.31 & 0.21 & 267 \\
\hline PI 163235* & Yellow & Pakistan & Cultivated PI & $82.5 \pm 5.0$ & $70.0 \pm 6.2$ & 12.5 & 12.7 & 0.87 & 0.86 & 0.25 & 101 \\
\hline PI 163238* & Orange/Yellow & India & Cultivated PI & $80.8 \pm 3.5$ & $65.8 \pm 4.4$ & 15.0 & 18.9 & 0.81 & 0.81 & 0.14 & 115 \\
\hline PI 163239 & Yellow & India & Cultivated PI & $84.9 \pm 3.9$ & $64.2 \pm 4.6$ & 20.7 & 24.1 & 0.76 & 0.82 & 0.34 & 112 \\
\hline PI 163240 & Yellow-Orange & India & Cultivated PI & $83.3 \pm 3.8$ & $61.7 \pm 12.2$ & 21.7 & 22.5 & 0.77 & 0.74 & 0.19 & 141 \\
\hline PI 163241 & Yellow/Orange & India & Cultivated PI & $71.8 \pm 4.5$ & $74.3 \pm 3.4$ & -2.5 & -5.6 & 1.06 & 0.80 & 0.26 & 120 \\
\hline PI 164943 & Yellow & Turkey & Cultivated PI & $75.0 \pm 5.9$ & $65.8 \pm 5.4$ & 9.2 & 6.8 & 0.93 & 0.73 & 0.18 & 147 \\
\hline PI 165522 & Orange & India & Cultivated PI & $75.0 \pm 6.1$ & $45.0 \pm 14.3$ & 30.0 & 36.9 & 0.63 & 0.49 & 0.12 & 214 \\
\hline PI 167143 & Purple-Yellow & Turkey & Cultivated PI & $60.0 \pm 5.6$ & $53.8 \pm 12.5$ & 6.2 & 3.0 & 0.97 & 0.46 & 0.20 & 223 \\
\hline PI 167211 & Purple & Turkey & Cultivated PI & $60.0 \pm 4.1$ & $52.5 \pm 5.9$ & 7.5 & 13.9 & 0.86 & 0.49 & 0.21 & 215 \\
\hline PI 176563 & Purple & Turkey & Cultivated PI & $67.5 \pm 5.0$ & $29.2 \pm 4.0$ & 38.3 & 54.9 & 0.45 & 0.29 & 0.24 & 272 \\
\hline PI 177381* & White & Turkey & Wild PI & $63.3 \pm 3.8$ & $39.2 \pm 9.0$ & 24.2 & 38.6 & 0.61 & 0.38 & 0.11 & 246 \\
\hline PI 181052* & Orange/Yellow & Pakistan & Cultivated PI & $56.7 \pm 5.4$ & $30.0 \pm 6.2$ & 26.7 & 49.1 & 0.51 & 0.28 & 0.13 & 276 \\
\hline PI 181880 & Orange/Yellow & Syria & Cultivated PI & $76.3 \pm 5.0$ & $80.8 \pm 8.1$ & -4.5 & -5.9 & 1.06 & 0.95 & 0.17 & 78 \\
\hline PI 187235 & Orange & Belgium & Cultivated PI & $69.2 \pm 3.0$ & $39.2 \pm 9.2$ & 30.0 & 43.3 & 0.57 & 0.41 & 0.10 & 241 \\
\hline PI 187236 & Orange & Belgium & Cultivated PI & $63.3 \pm 5.6$ & $52.0 \pm 5.2$ & 11.3 & 17.1 & 0.83 & 0.51 & 0.09 & 207 \\
\hline PI 193504 & Orange & Ethiopia & Cultivated PI & $82.5 \pm 5.3$ & $38.3 \pm 9.6$ & 44.2 & 50.6 & 0.49 & 0.46 & 0.16 & 224 \\
\hline PI 205997* & Orange & Sweden & Cultivated PI & $79.8 \pm 5.3$ & $59.2 \pm 10.1$ & 20.7 & 23.5 & 0.77 & 0.70 & 0.10 & 158 \\
\hline PI 211024 & Yellow & Afghanistan & Cultivated PI & $93.3 \pm 4.0$ & $84.2 \pm 6.1$ & 9.2 & 9.9 & 0.90 & 1.19 & 0.26 & 25 \\
\hline PI 211590 & Yellow & Afghanistan & Cultivated PI & $73.3 \pm 1.7$ & $54.2 \pm 3.3$ & 19.2 & 25.8 & 0.74 & 0.60 & 0.12 & 186 \\
\hline PI 218076* & Orange & Pakistan & Cultivated PI & $96.7 \pm 2.5$ & $91.7 \pm 1.7$ & 5.0 & 4.9 & 0.95 & 1.33 & 0.27 & 8 \\
\hline PI 222250 & Orange/White & Iran & Cultivated PI & $85.8 \pm 1.5$ & $73.2 \pm 4.4$ & 12.6 & 14.5 & 0.86 & 0.94 & 0.15 & 81 \\
\hline PI 223504 & Yellow-White & Afghanistan & Cultivated PI & $76.2 \pm 3.8$ & $67.5 \pm 6.7$ & 8.7 & 9.7 & 0.90 & 0.77 & 0.21 & 131 \\
\hline PI 225867 & Orange & Denmark & Cultivated PI & $87.5 \pm 4.2$ & $30.8 \pm 10.2$ & 56.7 & 65.0 & 0.35 & 0.41 & 0.08 & 242 \\
\hline PI 225868 & Orange & Denmark & Cultivated PI & $95.8 \pm 2.0$ & $82.2 \pm 5.0$ & 13.6 & 14.5 & 0.86 & 1.19 & 0.11 & 26 \\
\hline PI 225869* & Orange & Denmark & Cultivated PI & $90.6 \pm 5.4$ & $65.8 \pm 11.9$ & 24.7 & 26.6 & 0.73 & 0.90 & 0.13 & 90 \\
\hline PI 225870 & Orange & Denmark & Cultivated PI & $71.7 \pm 5.6$ & $33.3 \pm 7.7$ & 38.3 & 53.2 & 0.47 & 0.37 & 0.12 & 249 \\
\hline PI 225871 & Orange & Denmark & Cultivated PI & $75.8 \pm 4.7$ & $65.8 \pm 12.6$ & 10.0 & 13.2 & 0.87 & 0.77 & 0.10 & 132 \\
\hline PI 226043 & Orange & Japan & Cultivated PI & $83.3 \pm 3.8$ & $62.8 \pm 5.3$ & 20.6 & 23.8 & 0.76 & 0.78 & 0.14 & 129 \\
\hline PI 226309 & Orange & Mexico & Cultivated PI & $62.5 \pm 5.9$ & $55.8 \pm 5.7$ & 6.7 & 9.0 & 0.91 & 0.54 & 0.19 & 202 \\
\hline PI 226310 & Orange & Mexico & Cultivated PI & $96.7 \pm 2.1$ & $88.3 \pm 5.3$ & 8.3 & 8.9 & 0.91 & 1.29 & 0.20 & 13 \\
\hline PI 226464 & Orange & Iran & Cultivated PI & $74.4 \pm 5.4$ & $58.9 \pm 7.1$ & 15.5 & 17.6 & 0.82 & 0.65 & 0.18 & 173 \\
\hline PI 234620 & Orange & South Africa & Cultivated PI & $82.5 \pm 2.5$ & $60.0 \pm 9.2$ & 22.5 & 25.7 & 0.74 & 0.73 & 0.15 & 148 \\
\hline PI 234621 & Orange & South Africa & Cultivated PI & $94.3 \pm 1.5$ & $22.5 \pm 6.0$ & 71.8 & 76.3 & 0.24 & 0.32 & 0.16 & 262 \\
\hline PI 249535 & Orange & Spain & Cultivated PI & $87.5 \pm 1.1$ & $76.7 \pm 6.3$ & 10.8 & 12.4 & 0.88 & 1.01 & 0.15 & 59 \\
\hline PI 251228 & Purple & Afghanistan & Cultivated PI & $64.2 \pm 4.7$ & $47.5 \pm 1.7$ & 16.7 & 23.6 & 0.76 & 0.46 & 0.34 & 225 \\
\hline PI 256065 & Orange/Yellow & Afghanistan & Cultivated PI & $54.5 \pm 3.6$ & $30.0 \pm 15.0$ & 24.6 & 47.1 & 0.53 & 0.26 & 0.13 & 277 \\
\hline PI 256066* & Purple & Afghanistan & Cultivated PI & $74.2 \pm 4.2$ & $28.3 \pm 5.4$ & 45.8 & 62.0 & 0.38 & 0.32 & 0.23 & 263 \\
\hline PI 261648 & Orange & Netherlands & Cultivated PI & $89.2 \pm 4.0$ & $56.7 \pm 11.0$ & 32.5 & 34.5 & 0.65 & 0.74 & 0.14 & 142 \\
\hline PI 261650* & Orange & Netherlands & Cultivated PI & $96.7 \pm 1.1$ & $71.7 \pm 5.4$ & 25.0 & 25.9 & 0.74 & 1.04 & 0.13 & 52 \\
\hline PI 261781* & Orange & France & Cultivated PI & $82.5 \pm 3.4$ & $35.0 \pm 13.4$ & 47.5 & 57.6 & 0.42 & 0.44 & 0.20 & 231 \\
\hline PI 261782 & Orange & France & Cultivated PI & $86.0 \pm 6.0$ & $58.6 \pm 13.8$ & 27.3 & 32.2 & 0.68 & 0.78 & 0.11 & 130 \\
\hline PI 261783 & Orange & France & Cultivated PI & $56.7 \pm 6.0$ & $44.7 \pm 12.0$ & 12.0 & 17.0 & 0.83 & 0.38 & 0.27 & 247 \\
\hline PI 263023 & Orange & UK & Cultivated PI & $90.0 \pm 4.7$ & $79.2 \pm 5.5$ & 10.8 & 10.7 & 0.89 & 1.07 & 0.13 & 50 \\
\hline PI 264232 & Orange & France & Cultivated PI & $62.5 \pm 4.4$ & $31.7 \pm 8.0$ & 30.8 & 50.1 & 0.50 & 0.31 & 0.10 & 268 \\
\hline PI 264234 & Orange & France & Cultivated PI & $97.5 \pm 1.7$ & $91.7 \pm 4.0$ & 5.8 & 6.2 & 0.94 & 1.35 & 0.13 & 4 \\
\hline PI 264235 & Orange & France & Cultivated PI & $90.0 \pm 3.9$ & $83.2 \pm 5.2$ & 6.8 & 7.6 & 0.92 & 1.13 & 0.12 & 38 \\
\hline PI 264238 & Orange & France & Cultivated PI & $99.2 \pm 0.8$ & $79.2 \pm 9.4$ & 20.0 & 20.3 & 0.80 & 1.18 & 0.13 & 31 \\
\hline PI 264543 & Red/Orange & Japan & Cultivated PI & $76.7 \pm 4.8$ & $70.8 \pm 5.1$ & 5.8 & 5.3 & 0.95 & 0.81 & 0.21 & 116 \\
\hline PI 264669 & Orange & Germany & Cultivated PI & $73.3 \pm 3.3$ & $65.8 \pm 7.9$ & 7.5 & 8.9 & 0.91 & 0.72 & 0.12 & 152 \\
\hline PI 267090 & Orange & Tajikistan & Cultivated PI & $78.3 \pm 4.6$ & $53.3 \pm 4.8$ & 24.9 & 31.5 & 0.69 & 0.63 & 0.13 & 178 \\
\hline PI 267091 & Yellow & Soviet Union & Cultivated PI & $94.2 \pm 2.0$ & $81.7 \pm 4.6$ & 12.5 & 13.1 & 0.87 & 1.16 & 0.17 & 35 \\
\hline PI 268382 & Orange & Afghanistan & Cultivated PI & $80.0 \pm 2.6$ & $78.3 \pm 2.1$ & 1.7 & 1.7 & 0.98 & 0.94 & 0.11 & 82 \\
\hline PI 269316 & Orange & Sweden & Cultivated PI & $81.7 \pm 7.7$ & $40.0 \pm 6.8$ & 41.7 & 50.0 & 0.50 & 0.51 & 0.14 & 208 \\
\hline PI 269319 & Orange & Sweden & Cultivated PI & $75.0 \pm 5.3$ & $82.5 \pm 3.6$ & -7.5 & -15.5 & 1.16 & 0.92 & 0.11 & 86 \\
\hline
\end{tabular}


Supplemental Table 1. (Continued) Carrot accession, root color, country of origin, domestication status (DS), mean percent germination without heat stress (Nonstress) $\pm \mathrm{SE}$, mean percent germination with $35^{\circ} \mathrm{C}$ heat stress (Stress) $\pm \mathrm{SE}$, mean absolute decrease (AD), mean inhibition index (II), relative heat tolerance (RHT), mean heat tolerance index (HTI), hundred seed weight (HSW), and rank based on HTI.

\begin{tabular}{|c|c|c|c|c|c|c|c|c|c|c|c|}
\hline Merged & Root Color & Country & DS & Nonstress (\%) & Stress $(\%)$ & $\mathrm{AD}(\%)$ & II $(\%)$ & RHT & HTI & HSW & Rank \\
\hline PI 269322 & Orange & Sweden & Cultivated PI & $82.5 \pm 5.0$ & $45.8 \pm 11.4$ & 36.7 & 39.4 & 0.61 & 0.54 & 0.08 & 203 \\
\hline PI 269485* & White & Pakistan & Wild PI & $87.4 \pm 3.8$ & $74.2 \pm 7.6$ & 13.3 & 15.7 & 0.84 & 0.99 & 0.10 & 68 \\
\hline PI 269486* & Yellow & Pakistan & Cultivated PI & $69.4 \pm 6.0$ & $54.2 \pm 4.4$ & 15.2 & 17.1 & 0.83 & 0.55 & 0.25 & 198 \\
\hline PI 269487* & White & Pakistan & Wild PI & $88.3 \pm 3.6$ & $88.3 \pm 3.1$ & 0.0 & -1.2 & 1.01 & 1.17 & 0.11 & 33 \\
\hline PI 269488* & Orange & Pakistan & Cultivated PI & $95.0 \pm 3.2$ & $78.3 \pm 7.0$ & 16.7 & 18.3 & 0.82 & 1.13 & 0.12 & 39 \\
\hline PI 271044 & Purple-Orange & India & Cultivated PI & $52.5 \pm 4.8$ & $56.7 \pm 7.3$ & -4.2 & -14.3 & 1.14 & 0.44 & 0.28 & 232 \\
\hline PI 271470 & White & India & Cultivated PI & $69.8 \pm 2.5$ & $51.7 \pm 9.8$ & 18.1 & 26.8 & 0.73 & 0.55 & 0.29 & 199 \\
\hline PI 271471 & NA & India & Cultivated PI & $81.7 \pm 3.8$ & $74.2 \pm 2.0$ & 7.5 & 7.9 & 0.92 & 0.91 & 0.29 & 89 \\
\hline PI $274297 *$ & White & Pakistan & Wild PI & $62.5 \pm 6.9$ & $37.5 \pm 9.0$ & 25.0 & 40.7 & 0.59 & 0.38 & 0.12 & 248 \\
\hline PI 274298* & White & Pakistan & Wild PI & $76.6 \pm 5.8$ & $55.0 \pm 10.3$ & 21.6 & 23.2 & 0.77 & 0.61 & 0.13 & 184 \\
\hline PI 277285 & Orange & India & Cultivated PI & $71.7 \pm 5.4$ & $54.2 \pm 12.0$ & 17.5 & 22.3 & 0.78 & 0.59 & 0.11 & 193 \\
\hline PI 277668 & Orange & Netherlands & Cultivated PI & $96.7 \pm 2.1$ & $51.0 \pm 17.1$ & 45.7 & 47.3 & 0.53 & 0.74 & 0.09 & 143 \\
\hline PI 279764 & White & Libya & Wild PI & $78.3 \pm 3.6$ & $10.8 \pm 9.9$ & 67.5 & 85.6 & 0.14 & 0.12 & 0.20 & 286 \\
\hline PI 279776 & Purple & Egypt & Cultivated PI & $75.0 \pm 7.2$ & $70.0 \pm 8.4$ & 5.0 & 3.4 & 0.97 & 0.80 & 0.30 & 121 \\
\hline PI 279777 & Yellow & Egypt & Cultivated PI & $80.0 \pm 4.7$ & $56.7 \pm 6.7$ & 23.3 & 27.4 & 0.73 & 0.67 & 0.22 & 166 \\
\hline PI 280706* & White & Chile & Wild PI & $91.6 \pm 2.1$ & $58.3 \pm 11.0$ & 33.3 & 35.9 & 0.64 & 0.80 & 0.13 & 122 \\
\hline PI 285613 & Orange & Poland & Cultivated PI & $74.4 \pm 4.4$ & $61.7 \pm 8.9$ & 12.7 & 15.3 & 0.85 & 0.69 & 0.09 & 161 \\
\hline PI 294079 & Orange & Japan & Cultivated PI & $80.8 \pm 3.0$ & $50.0 \pm 9.0$ & 30.8 & 36.7 & 0.63 & 0.60 & 0.14 & 187 \\
\hline PI 294080 & Orange & Japan & Cultivated PI & $72.5 \pm 5.9$ & $65.0 \pm 3.9$ & 7.5 & 7.2 & 0.93 & 0.71 & 0.13 & 155 \\
\hline PI 294082 & Orange & Japan & Cultivated PI & $95.0 \pm 2.6$ & $88.3 \pm 1.1$ & 6.6 & 6.5 & 0.93 & 1.26 & 0.20 & 19 \\
\hline PI 294084 & Orange & Japan & Cultivated PI & $78.3 \pm 10.5$ & $65.0 \pm 12.3$ & 13.3 & 6.2 & 0.94 & 0.77 & 0.13 & 133 \\
\hline PI 294090 & Orange & Japan & Cultivated PI & $85.8 \pm 2.7$ & $64.2 \pm 8.9$ & 21.6 & 23.7 & 0.76 & 0.82 & 0.12 & 113 \\
\hline PI 295862 & White & Spain & Cultivated PI & $67.5 \pm 8.5$ & $25.8 \pm 11.1$ & 41.7 & 48.2 & 0.52 & 0.23 & 0.09 & 280 \\
\hline PI 306810 & Orange & New Zealand & Cultivated PI & $77.4 \pm 4.4$ & $51.7 \pm 10.5$ & 25.7 & 32.3 & 0.68 & 0.60 & 0.11 & 188 \\
\hline PI 319860 & Red & Japan & Cultivated PI & $78.3 \pm 6.2$ & $63.3 \pm 13.6$ & 15.0 & 14.1 & 0.86 & 0.74 & 0.17 & 144 \\
\hline PI 321688 & Red & Japan & Cultivated PI & $56.7 \pm 3.8$ & $56.7 \pm 3.1$ & 0.0 & -2.7 & 1.03 & 0.48 & 0.17 & 218 \\
\hline PI 325993 & Orange & Russia & Cultivated PI & $97.5 \pm 1.7$ & $81.7 \pm 12.5$ & 15.8 & 15.8 & 0.84 & 1.19 & 0.11 & 27 \\
\hline PI $326009^{*}$ & Orange & Uzbekistan & Cultivated PI & $91.6 \pm 2.8$ & $79.2 \pm 2.0$ & 12.5 & 13.0 & 0.87 & 1.09 & 0.12 & 46 \\
\hline PI 326010 & Orange & Tajikistan & Cultivated PI & $80.8 \pm 5.5$ & $60.8 \pm 3.0$ & 20.0 & 21.8 & 0.78 & 0.73 & 0.16 & 149 \\
\hline PI 341204 & Orange & France & Cultivated PI & $74.2 \pm 2.4$ & $42.5 \pm 5.1$ & 31.7 & 43.0 & 0.57 & 0.48 & 0.15 & 219 \\
\hline PI 341207 & Orange & France & Cultivated PI & $56.9 \pm 4.9$ & $37.5 \pm 9.9$ & 19.4 & 24.2 & 0.76 & 0.29 & 0.19 & 273 \\
\hline PI 341208 & Orange & France & Cultivated PI & $67.5 \pm 2.8$ & $48.9 \pm 9.6$ & 18.6 & 27.3 & 0.73 & 0.50 & 0.17 & 209 \\
\hline PI $344447^{*}$ & White & Iran & Wild PI & $60.0 \pm 1.8$ & $50.0 \pm 9.4$ & 10.0 & 15.4 & 0.85 & 0.45 & 0.20 & 230 \\
\hline PI 419109 & Yellow & China & Cultivated PI & $70.3 \pm 4.5$ & $58.3 \pm 7.2$ & 12.0 & 16.1 & 0.84 & 0.62 & 0.16 & 181 \\
\hline PI 419110 & Orange-Red & China & Cultivated PI & $80.8 \pm 3.3$ & $67.5 \pm 7.7$ & 13.3 & 16.5 & 0.84 & 0.83 & 0.15 & 110 \\
\hline PI 419184 & Orange & China & Cultivated PI & $95.0 \pm 3.2$ & $58.2 \pm 10.9$ & 36.8 & 37.7 & 0.62 & 0.82 & 0.14 & 114 \\
\hline PI 430524 & Yellow & Azerbaijan & Cultivated PI & $59.6 \pm 5.8$ & $53.3 \pm 5.6$ & 6.3 & 2.8 & 0.97 & 0.46 & 0.15 & 226 \\
\hline PI 430527 & Orange & Uzbekistan & Cultivated PI & $94.2 \pm 2.4$ & $69.2 \pm 3.5$ & 25.0 & 26.4 & 0.74 & 0.98 & 0.13 & 70 \\
\hline PI 430528 & Yellow & Uzbekistan & Cultivated PI & $87.5 \pm 2.8$ & $64.3 \pm 8.8$ & 23.2 & 25.6 & 0.74 & 0.84 & 0.13 & 106 \\
\hline PI 430529 & Yellow & Uzbekistan & Cultivated PI & $87.5 \pm 4.8$ & $67.5 \pm 8.0$ & 20.0 & 20.1 & 0.80 & 0.88 & 0.16 & 98 \\
\hline PI 430531 & Purple & Azerbaijan & Cultivated PI & $85.0 \pm 4.1$ & $60.0 \pm 13.8$ & 25.0 & 29.0 & 0.71 & 0.77 & 0.16 & 134 \\
\hline PI 430532 & Purple/White & Russia & Cultivated PI & $97.5 \pm 1.1$ & $84.2 \pm 8.6$ & 13.3 & 13.6 & 0.86 & 1.23 & 0.11 & 23 \\
\hline PI 430533 & Orange & Iraq & Cultivated PI & $94.2 \pm 2.4$ & $89.2 \pm 3.3$ & 5.0 & 5.3 & 0.95 & 1.27 & 0.10 & 16 \\
\hline PI 430534 & Yellow & Afghanistan & Cultivated PI & $94.3 \pm 2.0$ & $72.3 \pm 13.1$ & 22.0 & 23.8 & 0.76 & 1.03 & 0.11 & 56 \\
\hline PI 432898* & Orange/Yellow & China & Cultivated PI & $94.2 \pm 5.8$ & $71.7 \pm 13.5$ & 22.5 & 19.4 & 0.81 & 0.99 & 0.16 & 69 \\
\hline PI 432899 & Purple/Yellow/Orange & China & Cultivated PI & $70.0 \pm 4.7$ & $70.1 \pm 11.3$ & -0.1 & 0.6 & 0.99 & 0.76 & 0.16 & 138 \\
\hline PI 432900 & Orange & China & Cultivated PI & $56.9 \pm 5.4$ & $55.8 \pm 6.9$ & 1.1 & 0.7 & 0.99 & 0.50 & 0.14 & 210 \\
\hline PI 432901 & Orange & China & Cultivated PI & $90.0 \pm 2.6$ & $66.7 \pm 15.2$ & 23.3 & 23.5 & 0.77 & 0.87 & 0.15 & 100 \\
\hline PI 451752* & Yellow-White & Netherlands & Cultivated PI & $87.4 \pm 4.3$ & $67.5 \pm 10.4$ & 19.9 & 21.6 & 0.78 & 0.89 & 0.14 & 93 \\
\hline PI 451753* & Yellow & Netherlands & Cultivated PI & $68.3 \pm 5.3$ & $35.8 \pm 8.9$ & 32.5 & 46.4 & 0.54 & 0.37 & 0.20 & 250 \\
\hline PI 451754* & Yellow & Netherlands & Cultivated PI & $84.2 \pm 3.5$ & $55.8 \pm 9.9$ & 28.3 & 33.7 & 0.66 & 0.71 & 0.14 & 156 \\
\hline PI 451755 & Yellow & Netherlands & Cultivated PI & $85.8 \pm 3.0$ & $75.0 \pm 7.4$ & 10.8 & 12.4 & 0.88 & 0.97 & 0.09 & 73 \\
\hline PI 451756 & Yellow-White & Netherlands & Cultivated PI & $71.7 \pm 2.1$ & $46.4 \pm 10.5$ & 25.3 & 35.4 & 0.65 & 0.50 & 0.16 & 211 \\
\hline PI 451757* & White & Netherlands & Cultivated PI & $88.3 \pm 2.5$ & $75.8 \pm 8.0$ & 12.5 & 13.8 & 0.86 & 1.01 & 0.13 & 60 \\
\hline PI 451758 & Yellow & Netherlands & Cultivated PI & $88.3 \pm 5.1$ & $82.5 \pm 6.2$ & 5.8 & 4.0 & 0.96 & 1.09 & 0.11 & 47 \\
\hline PI 451759 & Yellow/White & Netherlands & Cultivated PI & $88.3 \pm 3.3$ & $60.8 \pm 6.1$ & 27.5 & 31.1 & 0.69 & 0.81 & 0.11 & 117 \\
\hline PI 451761* & Yellow-White & Netherlands & Cultivated PI & $94.2 \pm 2.4$ & $66.7 \pm 4.9$ & 27.5 & 29.4 & 0.71 & 0.95 & 0.14 & 79 \\
\hline PI 458857 & Orange & Russia & Cultivated PI & $83.3 \pm 4.0$ & $55.0 \pm 10.2$ & 28.3 & 32.9 & 0.67 & 0.68 & 0.13 & 164 \\
\hline PI 458858 & Orange & Russia & Cultivated PI & $96.7 \pm 1.1$ & $86.7 \pm 4.6$ & 10.0 & 10.1 & 0.90 & 1.26 & 0.11 & 20 \\
\hline PI 458859 & Orange & Russia & Cultivated PI & $58.9 \pm 2.5$ & $49.2 \pm 7.2$ & 9.7 & 14.2 & 0.86 & 0.43 & 0.15 & 234 \\
\hline PI 458860 & Orange & Russia & Cultivated PI & $95.8 \pm 1.5$ & $61.7 \pm 16.8$ & 34.2 & 35.1 & 0.65 & 0.88 & 0.10 & 99 \\
\hline PI 478369* & White & China & Wild PI & $70.8 \pm 5.5$ & $75.8 \pm 8.4$ & -5.0 & -10.3 & 1.10 & 0.81 & 0.13 & 118 \\
\hline PI 478370 & Orange & China & Cultivated PI & $62.7 \pm 3.7$ & $75.0 \pm 8.2$ & -12.3 & -22.3 & 1.22 & 0.70 & 0.23 & 159 \\
\hline PI 478883* & White & France & Wild PI & $83.4 \pm 1.3$ & $26.7 \pm 6.2$ & 56.7 & 68.0 & 0.32 & 0.33 & 0.16 & 258 \\
\hline PI 483348 & Orange & Japan & Cultivated PI & $79.8 \pm 6.7$ & $71.7 \pm 6.5$ & 8.1 & 3.0 & 0.97 & 0.83 & 0.18 & 111 \\
\hline PI 483352 & Orange & Japan & Cultivated PI & $88.3 \pm 3.3$ & $63.3 \pm 10.7$ & 25.0 & 28.3 & 0.72 & 0.85 & 0.17 & 103 \\
\hline PI 502239 & Orange & South Africa & Cultivated PI & $81.7 \pm 5.4$ & $67.5 \pm 13.0$ & 14.2 & 16.2 & 0.84 & 0.84 & 0.12 & 107 \\
\hline PI 502347 & Orange & Uzbekistan & Cultivated PI & $98.4 \pm 1.0$ & $93.3 \pm 3.1$ & 5.0 & 5.0 & 0.95 & 1.38 & 0.08 & 3 \\
\hline PI 502654* & Yellow/Purple & Pakistan & Cultivated PI & $63.7 \pm 5.1$ & $42.5 \pm 14.8$ & 21.2 & 30.4 & 0.70 & 0.41 & 0.34 & 243 \\
\hline PI 502655* & White & Pakistan & Wild PI & $82.5 \pm 5.3$ & $56.7 \pm 7.2$ & 25.8 & 28.8 & 0.71 & 0.69 & 0.18 & 162 \\
\hline PI 502656 & Yellow-White & Pakistan & Cultivated PI & $86.7 \pm 3.3$ & $69.2 \pm 6.3$ & 17.5 & 18.9 & 0.81 & 0.89 & 0.30 & 94 \\
\hline PI 502914 & Orange & Germany & Cultivated PI & $51.1 \pm 6.3$ & $47.5 \pm 8.0$ & 3.6 & -1.5 & 1.01 & 0.36 & 0.12 & 252 \\
\hline
\end{tabular}


Supplemental Table 1. (Continued) Carrot accession, root color, country of origin, domestication status (DS), mean percent germination without heat stress (Nonstress) $\pm \mathrm{SE}$, mean percent germination with $35^{\circ} \mathrm{C}$ heat stress (Stress) $\pm \mathrm{SE}$, mean absolute decrease (AD), mean inhibition index (II), relative heat tolerance (RHT), mean heat tolerance index (HTI), hundred seed weight (HSW), and rank based on HTI.

\begin{tabular}{|c|c|c|c|c|c|c|c|c|c|c|c|}
\hline Merged & Root Color & Country & $\mathrm{DS}$ & Nonstress $(\%)$ & Stress (\%) & $\mathrm{AD}(\%)$ & II $(\%)$ & RHT & HTI & HSW & Rank \\
\hline PI 502915* & Orange/White & Germany & Cultivated PI & $80.8 \pm 4.0$ & $45.0 \pm 10.5$ & 35.8 & 41.6 & 0.58 & 0.53 & 0.12 & 205 \\
\hline PI 502919 & Orange & Germany & Cultivated PI & $95.8 \pm 2.4$ & $69.2 \pm 15.4$ & 26.7 & 26.5 & 0.74 & 0.98 & 0.15 & 71 \\
\hline PI 503344 & Orange & Lithuania & Cultivated PI & $80.8 \pm 3.5$ & $83.2 \pm 4.8$ & -2.4 & -2.8 & 1.03 & 1.02 & 0.14 & 57 \\
\hline PI 503345* & Orange & Lithuania & Cultivated PI & $93.3 \pm 2.5$ & $76.0 \pm 8.7$ & 17.4 & 18.8 & 0.81 & 1.07 & 0.09 & 51 \\
\hline PI 506444 & Orange & Kazakhstan & Cultivated PI & $97.5 \pm 2.5$ & $76.7 \pm 7.7$ & 20.8 & 20.8 & 0.79 & 1.12 & 0.12 & 43 \\
\hline PI 506445 & Orange & Kazakhstan & Cultivated PI & $59.7 \pm 5.0$ & $32.9 \pm 8.1$ & 26.8 & 42.3 & 0.58 & 0.29 & 0.15 & 274 \\
\hline PI 508473 & Orange & South Korea & Cultivated PI & $52.2 \pm 2.9$ & $32.5 \pm 8.1$ & 19.7 & 37.9 & 0.62 & 0.26 & 0.13 & 278 \\
\hline PI 509433 & Purple/Yellow & Turkey & Cultivated PI & $96.7 \pm 1.7$ & $71.7 \pm 4.6$ & 25.0 & 25.8 & 0.74 & 1.04 & 0.16 & 53 \\
\hline PI 509434 & Red/White & Turkey & Cultivated PI & $95.0 \pm 2.2$ & $85.0 \pm 2.2$ & 10.0 & 10.0 & 0.90 & 1.21 & 0.18 & 24 \\
\hline PI 515990 & Orange & Hungary & Cultivated PI & $99.2 \pm 0.8$ & $57.5 \pm 8.1$ & 41.7 & 41.9 & 0.58 & 0.86 & 0.11 & 102 \\
\hline PI 515992 & Orange & Hungary & Cultivated PI & $96.7 \pm 1.7$ & $12.5 \pm 3.1$ & 84.2 & 87.0 & 0.13 & 0.18 & 0.10 & 284 \\
\hline PI 531326 & Orange & Hungary & Cultivated PI & $70.8 \pm 8.2$ & $62.1 \pm 8.8$ & 8.7 & 2.2 & 0.98 & 0.66 & 0.09 & 170 \\
\hline PI 535887* & Orange & Poland & Cultivated PI & $97.5 \pm 1.1$ & $69.2 \pm 10.4$ & 28.3 & 28.8 & 0.71 & 1.01 & 0.11 & 61 \\
\hline PI 537093 & Orange & South Korea & Cultivated PI & $90.8 \pm 3.8$ & $85.0 \pm 3.2$ & 5.8 & 5.3 & 0.95 & 1.16 & 0.20 & 36 \\
\hline PI 540419 & Yellow & Uzbekistan & Cultivated PI & $78.3 \pm 8.6$ & $83.3 \pm 5.1$ & -5.0 & -17.8 & 1.18 & 0.97 & 0.12 & 74 \\
\hline PI 540422 & Yellow & Uzbekistan & Cultivated PI & $71.4 \pm 1.7$ & $55.4 \pm 8.6$ & 16.0 & 22.3 & 0.78 & 0.60 & 0.10 & 189 \\
\hline PI 632381 & Yellow & United States & Cultivated PI & $99.2 \pm 0.8$ & $85.0 \pm 12.1$ & 14.2 & 14.2 & 0.86 & 1.27 & 0.14 & 17 \\
\hline PI 632382 & Orange & United States & Cultivated PI & $95.8 \pm 2.4$ & $78.8 \pm 7.8$ & 17.0 & 17.3 & 0.83 & 1.13 & 0.11 & 40 \\
\hline PI 632383* & Orange & United States & Cultivated PI & $90.0 \pm 9.0$ & $59.2 \pm 17.5$ & 30.8 & 40.8 & 0.59 & 0.89 & 0.14 & 95 \\
\hline PI 632384* & Orange & United States & Cultivated PI & $96.7 \pm 1.7$ & $69.2 \pm 4.4$ & 27.5 & 28.5 & 0.72 & 1.01 & 0.12 & 62 \\
\hline PI 632385 & Orange & United States & Cultivated PI & $99.2 \pm 0.8$ & $86.8 \pm 4.7$ & 12.3 & 12.3 & 0.88 & 1.29 & 0.15 & 14 \\
\hline PI 632386 & Orange & United States & Cultivated PI & $94.1 \pm 2.4$ & $70.8 \pm 13.4$ & 23.3 & 24.0 & 0.76 & 1.00 & 0.12 & 64 \\
\hline PI 632389 & Orange & Netherlands & Cultivated PI & $98.3 \pm 1.7$ & $80.8 \pm 12.3$ & 17.5 & 17.4 & 0.83 & 1.19 & 0.13 & 28 \\
\hline PI 632393 & Orange & United States & Cultivated PI & $95.0 \pm 2.2$ & $88.3 \pm 4.2$ & 6.7 & 6.9 & 0.93 & 1.26 & 0.12 & 21 \\
\hline PI 634651 & Orange & United States & Cultivated PI & $99.2 \pm 0.8$ & $90.0 \pm 4.8$ & 9.2 & 9.2 & 0.91 & 1.34 & 0.12 & 6 \\
\hline PI 634652 & Yellow & United States & Cultivated PI & $96.7 \pm 2.1$ & $85.8 \pm 4.2$ & 10.8 & 11.2 & 0.89 & 1.25 & 0.09 & 22 \\
\hline PI 634653 & Orange & United States & Cultivated PI & $97.5 \pm 1.1$ & $75.0 \pm 10.2$ & 22.5 & 22.6 & 0.77 & 1.09 & 0.12 & 48 \\
\hline PI 634654 & Orange & United States & Cultivated PI & $96.7 \pm 1.7$ & $71.7 \pm 12.0$ & 25.0 & 25.8 & 0.74 & 1.04 & 0.08 & 54 \\
\hline PI 634655 & Orange & United States & Cultivated PI & $96.7 \pm 2.1$ & $59.2 \pm 12.8$ & 37.5 & 37.9 & 0.62 & 0.85 & 0.13 & 104 \\
\hline PI 634657 & Orange & Netherlands & Cultivated PI & $95.0 \pm 1.8$ & $67.5 \pm 17.2$ & 27.5 & 29.4 & 0.71 & 0.97 & 0.14 & 75 \\
\hline PI 642755 & Orange & United States & Cultivated PI & $97.5 \pm 1.1$ & $55.0 \pm 16.2$ & 42.5 & 43.7 & 0.56 & 0.81 & 0.13 & 119 \\
\hline PI 642756 & Orange & Netherlands & Cultivated PI & $100.0 \pm 0.0$ & $88.3 \pm 6.5$ & 11.7 & 11.7 & 0.88 & 1.33 & 0.11 & 9 \\
\hline PI 642761 & Orange & United States & Cultivated PI & $96.7 \pm 1.7$ & $89.2 \pm 4.0$ & 7.5 & 7.8 & 0.92 & 1.30 & 0.14 & 12 \\
\hline PI 643114 & White & United States & Cultivated PI & $99.2 \pm 0.8$ & $97.5 \pm 1.1$ & 1.7 & 1.7 & 0.98 & 1.45 & 0.13 & 1 \\
\hline PI 643118 & White & United States & Cultivated PI & $97.5 \pm 1.7$ & $62.5 \pm 5.9$ & 35.0 & 36.1 & 0.64 & 0.92 & 0.09 & 87 \\
\hline PI 643119 & Orange & France & Cultivated PI & $100.0 \pm 0.0$ & $85.1 \pm 8.2$ & 14.9 & 14.9 & 0.85 & 1.28 & 0.09 & 15 \\
\hline PI 652121 & Orange & Japan & Cultivated PI & $94.2 \pm 2.4$ & $78.3 \pm 5.9$ & 15.9 & 16.7 & 0.83 & 1.11 & 0.14 & 44 \\
\hline PI 652136 & Orange & Japan & Cultivated PI & $85.8 \pm 2.7$ & $78.1 \pm 5.8$ & 7.8 & 8.0 & 0.92 & 1.00 & 0.14 & 65 \\
\hline PI 652137 & Orange & Japan & Cultivated PI & $85.8 \pm 6.0$ & $69.2 \pm 5.7$ & 16.7 & 18.6 & 0.81 & 0.90 & 0.12 & 91 \\
\hline PI 652138 & Orange & Japan & Cultivated PI & $90.7 \pm 2.7$ & $54.2 \pm 6.3$ & 36.5 & 39.1 & 0.61 & 0.73 & 0.15 & 150 \\
\hline PI 652152 & Orange & UK & Cultivated PI & $59.2 \pm 8.0$ & $32.5 \pm 11.8$ & 26.7 & 43.8 & 0.56 & 0.30 & 0.11 & 269 \\
\hline PI 652153* & Orange & Netherlands & Cultivated PI & $90.0 \pm 3.4$ & $72.5 \pm 6.6$ & 17.5 & 18.6 & 0.81 & 0.98 & 0.12 & 72 \\
\hline PI 652154 & Orange & Netherlands & Cultivated PI & $51.2 \pm 6.9$ & $64.2 \pm 4.4$ & -13.0 & -35.7 & 1.36 & 0.49 & 0.10 & 216 \\
\hline PI 652155 & Orange & Hungary & Cultivated PI & $69.2 \pm 3.8$ & $46.7 \pm 5.3$ & 22.5 & 30.1 & 0.70 & 0.48 & 0.10 & 220 \\
\hline PI 652156* & Orange & Czech Republic & Cultivated PI & $77.8 \pm 2.6$ & $50.8 \pm 9.5$ & 26.9 & 33.9 & 0.66 & 0.59 & 0.10 & 194 \\
\hline PI 652157 & Orange & Soviet Union & Cultivated PI & $75.8 \pm 5.8$ & $74.5 \pm 9.6$ & 1.3 & -2.9 & 1.03 & 0.84 & 0.11 & 108 \\
\hline PI 652158 & Orange & Georgia & Cultivated PI & $74.2 \pm 3.5$ & $55.8 \pm 10.1$ & 18.3 & 25.4 & 0.75 & 0.63 & 0.11 & 179 \\
\hline PI 652163 & Orange & Netherlands & Cultivated PI & $74.2 \pm 3.0$ & $56.0 \pm 10.2$ & 18.2 & 24.9 & 0.75 & 0.63 & 0.10 & 180 \\
\hline PI 652171 & Orange & Netherlands & Cultivated PI & $78.3 \pm 2.1$ & $64.2 \pm 5.7$ & 14.2 & 16.9 & 0.83 & 0.75 & 0.14 & 139 \\
\hline PI 652173 & Orange & UK & Cultivated PI & $65.0 \pm 4.3$ & $66.7 \pm 7.4$ & -1.7 & -5.0 & 1.05 & 0.65 & 0.11 & 174 \\
\hline PI 652179 & Orange/Yellow & United States & Cultivated PI & $80.2 \pm 4.3$ & $70.8 \pm 6.0$ & 9.3 & 9.0 & 0.91 & 0.84 & 0.16 & 109 \\
\hline PI 652188 & Purple & China & Cultivated PI & $69.2 \pm 5.1$ & $63.3 \pm 5.9$ & 5.8 & 6.8 & 0.93 & 0.67 & 0.10 & 167 \\
\hline PI 652206* & Orange & Bulgaria & Cultivated PI & $90.8 \pm 3.0$ & $87.5 \pm 2.8$ & 3.3 & 3.2 & 0.97 & 1.19 & 0.16 & 29 \\
\hline PI 652207 & Orange & China & Cultivated PI & $90.8 \pm 4.9$ & $56.7 \pm 13.3$ & 34.2 & 36.4 & 0.64 & 0.77 & 0.08 & 135 \\
\hline PI 652208 & Orange/Yellow/Red & China & Cultivated PI & $99.2 \pm 0.8$ & $94.2 \pm 3.3$ & 5.0 & 5.0 & 0.95 & 1.40 & 0.15 & 2 \\
\hline PI 652209 & Yellow & China & Cultivated PI & $89.2 \pm 3.0$ & $75.4 \pm 6.7$ & 13.8 & 15.0 & 0.85 & 1.01 & 0.18 & 63 \\
\hline PI 652242* & Yellow/White & India & Cultivated PI & $83.3 \pm 3.1$ & $64.2 \pm 7.6$ & 19.2 & 21.3 & 0.79 & 0.79 & 0.17 & 126 \\
\hline PI 652243 & Yellow & Turkey & Cultivated PI & $78.1 \pm 4.1$ & $60.8 \pm 13.2$ & 17.2 & 19.7 & 0.80 & 0.70 & 0.28 & 160 \\
\hline PI 652245 & White & India & Wild PI & $75.0 \pm 6.6$ & $53.3 \pm 4.8$ & 21.7 & 25.8 & 0.74 & 0.61 & 0.23 & 185 \\
\hline PI 652246 & Orange & Russia & Cultivated PI & $66.7 \pm 7.0$ & $75.8 \pm 4.2$ & -9.2 & -19.9 & 1.20 & 0.77 & 0.24 & 136 \\
\hline PI 652247 & Orange & Russia & Cultivated PI & $65.0 \pm 4.1$ & $53.3 \pm 12.2$ & 11.7 & 21.6 & 0.78 & 0.55 & 0.18 & 200 \\
\hline PI 652248 & Orange & Russia & Cultivated PI & $95.0 \pm 2.2$ & $94.2 \pm 3.3$ & 0.8 & 0.5 & 1.00 & 1.34 & 0.21 & 7 \\
\hline PI 652249 & Orange & Russia & Cultivated PI & $90.0 \pm 2.6$ & $69.2 \pm 4.6$ & 20.8 & 23.2 & 0.77 & 0.94 & 0.15 & 83 \\
\hline PI 652252 & Purple-Yellow & India & Cultivated PI & $61.8 \pm 5.0$ & $40.0 \pm 8.1$ & 21.8 & 31.0 & 0.69 & 0.36 & 0.23 & 253 \\
\hline PI 652253 & Red/Yellow & India & Cultivated PI & $50.0 \pm 3.7$ & $56.2 \pm 2.9$ & -6.2 & -14.8 & 1.15 & 0.42 & 0.25 & 237 \\
\hline PI 652255 & Orange/Purple & India & Cultivated PI & $96.7 \pm 1.7$ & $74.2 \pm 5.1$ & 22.5 & 23.1 & 0.77 & 1.08 & 0.20 & 49 \\
\hline PI 652256 & Purple/Yellow & India & Cultivated PI & $79.8 \pm 5.2$ & $63.3 \pm 9.6$ & 16.5 & 16.7 & 0.83 & 0.74 & 0.20 & 145 \\
\hline PI 652257 & Red & India & Cultivated PI & $90.8 \pm 2.0$ & $68.4 \pm 8.4$ & 22.4 & 24.6 & 0.75 & 0.94 & 0.18 & 84 \\
\hline PI 652258 & Orange & India & Cultivated PI & $78.7 \pm 2.7$ & $55.1 \pm 5.9$ & 23.7 & 29.3 & 0.71 & 0.65 & 0.20 & 175 \\
\hline PI 652260 & Orange/Yellow & India & Cultivated PI & $85.0 \pm 2.6$ & $78.3 \pm 7.7$ & 6.7 & 7.4 & 0.93 & 1.00 & 0.15 & 66 \\
\hline PI 652261 & Red & India & Cultivated PI & $85.0 \pm 4.7$ & $78.3 \pm 11.5$ & 6.7 & 5.8 & 0.94 & 1.00 & 0.27 & 67 \\
\hline PI 652276 & Orange/Yellow & Tajikistan & Cultivated PI & $65.8 \pm 7.2$ & $42.5 \pm 8.5$ & 23.3 & 32.4 & 0.68 & 0.43 & 0.22 & 235 \\
\hline
\end{tabular}


Supplemental Table 1. (Continued) Carrot accession, root color, country of origin, domestication status (DS), mean percent germination without heat stress (Nonstress) $\pm \mathrm{SE}$, mean percent germination with $35^{\circ} \mathrm{C}$ heat stress (Stress) $\pm \mathrm{SE}$, mean absolute decrease (AD), mean inhibition index (II), relative heat tolerance (RHT), mean heat tolerance index (HTI), hundred seed weight (HSW), and rank based on HTI.

\begin{tabular}{|c|c|c|c|c|c|c|c|c|c|c|c|}
\hline Merged & Root Color & Country & DS & Nonstress $(\%)$ & Stress $(\%)$ & $\mathrm{AD}(\%)$ & II $(\%)$ & RHT & HTI & HSW & Rank \\
\hline PI 652277 & Orange & Mongolia & Cultivated PI & $91.6 \pm 2.5$ & $65.8 \pm 15.0$ & 25.8 & 27.5 & 0.72 & 0.90 & 0.11 & 92 \\
\hline PI 652288 & Orange & Kazakhstan & Cultivated PI & $60.0 \pm 7.0$ & $54.2 \pm 11.4$ & 5.8 & -8.4 & 1.08 & 0.44 & 0.11 & 233 \\
\hline PI 652290* & White & Poland & Wild PI & $82.5 \pm 4.2$ & $46.6 \pm 8.0$ & 36.0 & 44.3 & 0.56 & 0.59 & 0.12 & 195 \\
\hline PI 652291* & White & Portugal & Wild PI & $83.3 \pm 3.1$ & $17.5 \pm 11.2$ & 65.8 & 78.4 & 0.22 & 0.21 & 0.15 & 283 \\
\hline PI 652334 & Purple & Syria & Cultivated PI & $85.8 \pm 2.4$ & $65.8 \pm 5.7$ & 20.0 & 22.7 & 0.77 & 0.85 & 0.15 & 105 \\
\hline PI 652335 & Purple & Syria & Cultivated PI & $75.3 \pm 4.5$ & $36.7 \pm 3.8$ & 38.6 & 51.3 & 0.49 & 0.42 & 0.19 & 238 \\
\hline PI 652336 & Purple & Syria & Cultivated PI & $57.5 \pm 5.1$ & $58.3 \pm 6.4$ & -0.8 & -6.3 & 1.06 & 0.50 & 0.17 & 212 \\
\hline PI 652338* & White & Syria & Wild PI & $82.5 \pm 4.6$ & $59.2 \pm 9.1$ & 23.3 & 26.0 & 0.74 & 0.72 & 0.23 & 153 \\
\hline PI $652341 *$ & White & Syria & Wild PI & $89.2 \pm 2.4$ & $25.0 \pm 13.7$ & 64.2 & 72.6 & 0.27 & 0.34 & 0.15 & 255 \\
\hline PI 652344* & White & Syria & Wild PI & $81.7 \pm 2.1$ & $27.5 \pm 16.0$ & 54.2 & 64.7 & 0.35 & 0.32 & 0.21 & 264 \\
\hline PI 652346* & White & Syria & Wild PI & $89.2 \pm 3.5$ & $34.2 \pm 16.0$ & 55.0 & 61.3 & 0.39 & 0.46 & 0.14 & 227 \\
\hline PI 652347 & White & Syria & Wild PI & $82.2 \pm 3.9$ & $28.3 \pm 9.7$ & 53.9 & 61.7 & 0.38 & 0.32 & 0.13 & 265 \\
\hline PI 652348* & White & Turkey & Wild PI & $58.3 \pm 6.5$ & $31.7 \pm 9.6$ & 26.7 & 44.4 & 0.56 & 0.29 & 0.18 & 275 \\
\hline PI 652349* & White & Turkey & Wild PI & $83.3 \pm 7.5$ & $27.5 \pm 8.6$ & 55.8 & 63.9 & 0.36 & 0.33 & 0.10 & 259 \\
\hline PI 652351 & White & Turkey & Wild PI & $85.8 \pm 4.4$ & $28.3 \pm 12.8$ & 57.5 & 64.8 & 0.35 & 0.34 & 0.14 & 256 \\
\hline PI 652352* & White & Turkey & Wild PI & $87.5 \pm 3.4$ & $54.2 \pm 7.7$ & 33.3 & 36.1 & 0.64 & 0.69 & 0.16 & 163 \\
\hline PI 652353* & White & Turkey & Wild PI & $88.3 \pm 2.8$ & $60.8 \pm 11.4$ & 27.5 & 30.2 & 0.70 & 0.80 & 0.11 & 123 \\
\hline PI 652354* & White & Turkey & Wild PI & $90.8 \pm 4.4$ & $4.2 \pm 0.8$ & 86.7 & 95.6 & 0.04 & 0.06 & 0.16 & 288 \\
\hline PI 652356* & White & Turkey & Wild PI & $90.8 \pm 3.0$ & $45.8 \pm 13.2$ & 45.0 & 48.9 & 0.51 & 0.62 & 0.15 & 182 \\
\hline PI 652358* & White & Turkey & Wild PI & $66.7 \pm 5.1$ & $60.0 \pm 10.8$ & 6.7 & 7.5 & 0.92 & 0.60 & 0.10 & 190 \\
\hline PI 652359* & White & Turkey & Wild PI & $91.7 \pm 3.1$ & $16.7 \pm 4.9$ & 75.0 & 81.7 & 0.18 & 0.23 & 0.11 & 281 \\
\hline PI $652362 *$ & White & Turkey & Wild PI & $86.7 \pm 2.8$ & $41.3 \pm 8.0$ & 45.4 & 51.6 & 0.48 & 0.53 & 0.12 & 206 \\
\hline PI 652364* & White & Turkey & Wild PI & $83.3 \pm 1.7$ & $53.3 \pm 7.8$ & 30.0 & 35.4 & 0.65 & 0.66 & 0.14 & 171 \\
\hline PI 652368* & White & Turkey & Wild PI & $94.2 \pm 4.0$ & $55.8 \pm 10.4$ & 38.3 & 39.9 & 0.60 & 0.79 & 0.16 & 127 \\
\hline PI 652369* & White & Turkey & Wild PI & $94.7 \pm 2.0$ & $67.2 \pm 4.9$ & 27.6 & 28.9 & 0.71 & 0.95 & 0.08 & 80 \\
\hline PI 652370* & White & Turkey & Wild PI & $86.7 \pm 5.4$ & $55.0 \pm 7.9$ & 31.7 & 34.4 & 0.66 & 0.71 & 0.16 & 157 \\
\hline PI 652372* & White & Turkey & Wild PI & $75.8 \pm 4.0$ & $44.2 \pm 6.4$ & 31.7 & 39.0 & 0.61 & 0.49 & 0.09 & 217 \\
\hline PI 652373* & White & Turkey & Wild PI & $69.2 \pm 6.6$ & $33.2 \pm 11.0$ & 35.9 & 45.1 & 0.55 & 0.33 & 0.10 & 260 \\
\hline PI 652374 & Yellow & Turkey & Cultivated PI & $100.0 \pm 0.0$ & $75.8 \pm 16.5$ & 24.2 & 24.2 & 0.76 & 1.14 & 0.17 & 37 \\
\hline PI 652379* & White & Turkey & Wild PI & $89.2 \pm 3.5$ & $31.7 \pm 13.0$ & 57.5 & 63.9 & 0.36 & 0.42 & 0.06 & 239 \\
\hline PI 652380* & White & Turkey & Wild PI & $72.5 \pm 4.2$ & $31.7 \pm 12.2$ & 40.8 & 54.2 & 0.46 & 0.33 & 0.08 & 261 \\
\hline PI 652382* & White & Turkey & Wild PI & $82.4 \pm 4.9$ & $18.3 \pm 4.9$ & 64.1 & 76.2 & 0.24 & 0.22 & 0.16 & 282 \\
\hline PI 652384* & White & Turkey & Wild PI & $82.5 \pm 4.2$ & $53.8 \pm 11.3$ & 28.7 & 31.0 & 0.69 & 0.64 & 0.14 & 176 \\
\hline PI 652387* & White & Turkey & Wild PI & $62.8 \pm 4.6$ & $35.0 \pm 15.0$ & 27.8 & 37.3 & 0.63 & 0.30 & 0.12 & 270 \\
\hline PI 652388* & White & Turkey & Wild PI & $80.7 \pm 6.3$ & $28.3 \pm 14.6$ & 52.4 & 63.7 & 0.36 & 0.34 & 0.11 & 257 \\
\hline PI 652391* & White & Turkey & Wild PI & $82.5 \pm 2.8$ & $24.2 \pm 15.6$ & 58.3 & 70.9 & 0.29 & 0.30 & 0.18 & 271 \\
\hline PI 652392* & White & Turkey & Wild PI & $65.8 \pm 4.7$ & $25.0 \pm 15.9$ & 40.8 & 61.5 & 0.38 & 0.24 & 0.15 & 279 \\
\hline PI 652393* & White & Turkey & Wild PI & $77.4 \pm 3.5$ & $37.5 \pm 8.6$ & 39.9 & 50.4 & 0.50 & 0.43 & 0.17 & 236 \\
\hline PI 652394* & White & Turkey & Wild PI & $85.0 \pm 3.4$ & $69.2 \pm 6.5$ & 15.9 & 18.5 & 0.82 & 0.89 & 0.12 & 96 \\
\hline PI 652396* & White & Turkey & Wild PI & $71.5 \pm 6.0$ & $44.6 \pm 6.7$ & 26.8 & 33.2 & 0.67 & 0.46 & 0.20 & 228 \\
\hline PI 652398* & White & Turkey & Wild PI & $80.6 \pm 4.4$ & $53.3 \pm 10.3$ & 27.3 & 34.0 & 0.66 & 0.66 & 0.18 & 172 \\
\hline PI 652399* & White & Turkey & Wild PI & $70.7 \pm 3.4$ & $45.0 \pm 11.3$ & 25.7 & 38.7 & 0.61 & 0.50 & 0.10 & 213 \\
\hline PI 652400 & Orange & Turkey & Cultivated PI & $95.8 \pm 2.4$ & $94.2 \pm 4.9$ & 1.6 & 1.1 & 0.99 & 1.35 & 0.18 & 5 \\
\hline PI 652401 & Orange & Turkey & Cultivated PI & $90.0 \pm 7.2$ & $85.8 \pm 3.5$ & 4.2 & 2.3 & 0.98 & 1.18 & 0.15 & 32 \\
\hline PI 652402 & Orange & Turkey & Cultivated PI & $96.7 \pm 2.1$ & $77.5 \pm 4.4$ & 19.2 & 19.8 & 0.80 & 1.13 & 0.15 & 41 \\
\hline PI 652403 & Orange & Turkey & Cultivated PI & $94.2 \pm 1.5$ & $94.2 \pm 2.7$ & 0.0 & -0.3 & 1.00 & 1.33 & 0.22 & 10 \\
\hline PI 652404 & Orange & Turkey & Cultivated PI & $93.3 \pm 1.1$ & $56.7 \pm 7.9$ & 36.7 & 39.2 & 0.61 & 0.79 & 0.14 & 128 \\
\hline PI 652405 & Orange & Turkey & Cultivated PI & $97.5 \pm 1.1$ & $76.7 \pm 15.4$ & 20.8 & 21.7 & 0.78 & 1.13 & 0.15 & 42 \\
\hline PI 652406* & White & Turkey & Wild PI & $82.5 \pm 2.5$ & $58.3 \pm 7.9$ & 24.2 & 30.0 & 0.70 & 0.73 & 0.14 & 151 \\
\hline PI $652407^{*}$ & White & Turkey & Wild PI & $77.5 \pm 7.9$ & $35.8 \pm 10.9$ & 41.7 & 58.0 & 0.42 & 0.47 & 0.09 & 221 \\
\hline PI 652409* & White & Turkey & Wild PI & $88.3 \pm 2.1$ & $51.8 \pm 9.9$ & 36.5 & 39.9 & 0.60 & 0.67 & 0.11 & 168 \\
\hline PI 652410* & NA & India & Cultivated PI & $95.8 \pm 3.3$ & $88.3 \pm 2.1$ & 7.5 & 7.1 & 0.93 & 1.27 & 0.26 & 18 \\
\hline PI 652411* & White & France & Wild PI & $88.3 \pm 2.8$ & $51.0 \pm 11.4$ & 37.4 & 42.4 & 0.58 & 0.68 & 0.09 & 165 \\
\hline Brasilia & Orange & Brazil & Cultivated PI & $54.7 \pm 3.0$ & $42.0 \pm 4.1$ & 12.7 & 23.2 & 0.77 & 0.35 & 0.11 & 264 \\
\hline B0493B & Orange & United States & Inbred & $55.8 \pm 6.8$ & $0.0 \pm 0.0$ & 55.8 & 100.0 & 0.00 & 0.00 & 0.15 & 289 \\
\hline B2327B & Orange & United States & Inbred & $67.5 \pm 8.2$ & $46.7 \pm 6.9$ & 20.8 & 21.6 & 0.78 & 0.45 & 0.19 & 229 \\
\hline B2566B & Orange & United States & Inbred & $90.0 \pm 3.7$ & $28.3 \pm 9.6$ & 61.7 & 67.5 & 0.32 & 0.38 & 0.13 & 245 \\
\hline B5208B & Orange & United States & Inbred & $90.8 \pm 3.3$ & $68.3 \pm 13.5$ & 22.5 & 25.6 & 0.74 & 0.95 & 0.12 & 76 \\
\hline B5238B & Orange & United States & Inbred & $69.2 \pm 5.8$ & $49.2 \pm 11.5$ & 20.0 & 29.7 & 0.70 & 0.54 & 0.20 & 201 \\
\hline B6279B & Orange & United States & Inbred & $63.3 \pm 7.0$ & $38.3 \pm 9.5$ & 25.0 & 42.3 & 0.58 & 0.40 & 0.12 & 244 \\
\hline B7254B & Orange & United States & Inbred & $58.3 \pm 6.4$ & $7.5 \pm 4.8$ & 50.8 & 85.9 & 0.14 & 0.06 & 0.18 & 287 \\
\hline $\mathrm{DH} 1^{\mathrm{y}}$ & Orange & Netherlands & Inbred & $87.5 \pm 2.8$ & $23.3 \pm 3.3$ & 64.2 & 73.0 & 0.27 & 0.31 & 0.20 & 266 \\
\hline L1408B & Orange & United States & Inbred & $65.0 \pm 1.8$ & $35.0 \pm 3.9$ & 30.0 & 45.6 & 0.54 & 0.34 & 0.18 & 254 \\
\hline $\mathrm{Nb} 4001 \mathrm{~B}$ & Orange & United States & Inbred & $83.2 \pm 2.2$ & $56.2 \pm 8.2$ & 26.9 & 32.8 & 0.67 & 0.71 & 0.15 & 154 \\
\hline $\mathrm{Nb} 4002 \mathrm{~B}$ & Orange & United States & Inbred & $88.3 \pm 8.8$ & $65.8 \pm 9.3$ & 22.5 & 28.0 & 0.72 & 0.93 & 0.15 & 85 \\
\hline $\mathrm{Nb} 6526 \mathrm{~B}$ & Orange & United States & Inbred & $82.5 \pm 5.1$ & $59.8 \pm 6.5$ & 22.7 & 25.0 & 0.75 & 0.73 & 0.16 & 146 \\
\hline Ns5154 & Orange & United States & Inbred & $96.7 \pm 1.7$ & $60.8 \pm 8.8$ & 35.8 & 36.4 & 0.64 & 0.88 & 0.17 & 97 \\
\hline P1129B & Purple & United States & Inbred & $93.3 \pm 2.1$ & $33.3 \pm 7.2$ & 60.0 & 63.8 & 0.36 & 0.46 & 0.18 & 222 \\
\hline R6636B & Red & United States & Inbred & $84.2 \pm 10.1$ & $53.3 \pm 17.1$ & 30.8 & 19.8 & 0.80 & 0.64 & 0.20 & 177 \\
\hline A & Orange & United States & Hybrid & $70.7 \pm 3.8$ & $30.0 \pm 2.5$ & 40.7 & 57.6 & 0.42 & 0.32 & 0.20 & 262 \\
\hline B & Orange & United States & Hybrid & $59.3 \pm 4.6$ & $16.0 \pm 4.5$ & 43.3 & 73.0 & 0.27 & 0.14 & 0.19 & 284 \\
\hline $\mathrm{C}$ & Orange & United States & Hybrid & $70.7 \pm 3.4$ & $45.3 \pm 4.1$ & 25.4 & 35.9 & 0.64 & 0.48 & 0.16 & 218 \\
\hline
\end{tabular}


Supplemental Table 1. (Continued) Carrot accession, root color, country of origin, domestication status (DS), mean percent germination without heat stress (Nonstress) $\pm \mathrm{SE}$, mean percent germination with $35^{\circ} \mathrm{C}$ heat stress (Stress) $\pm \mathrm{SE}$, mean absolute decrease (AD), mean inhibition index (II), relative heat tolerance (RHT), mean heat tolerance index (HTI), hundred seed weight (HSW), and rank based on HTI.

\begin{tabular}{|c|c|c|c|c|c|c|c|c|c|c|c|}
\hline Merged & Root Color & Country & DS & Nonstress (\%) & Stress (\%) & $\mathrm{AD}(\%)$ & II (\%) & RHT & HTI & HSW & Rank \\
\hline $\mathrm{F}$ & Purple & United States & Hybrid & $80.0 \pm 6.6$ & $62.5 \pm 9.2$ & 17.5 & 21.4 & 0.79 & 0.77 & 0.19 & 137 \\
\hline G & Orange & United States & Hybrid & $89.0 \pm 1.6$ & $68.3 \pm 9.0$ & 20.7 & 23.4 & 0.77 & 0.92 & 0.20 & 88 \\
\hline
\end{tabular}

${ }^{\mathrm{z}} \mathrm{PI}=$ plant introduction.

${ }^{\mathrm{y}}$ Developed and donated by Rijk Zwaan. 